\title{
EXPECTATIVAS EMPRESARIAIS, INVESTIMENTO AGREGADO E EMPREGO: UMA ANÁLISE CONSIDERANDO OS EFEITOS DAS CREDIBILIDADES MONETÁRIA E FISCAL NO BRASIL
}

\author{
Gabriel Caldas Montes* \\ Caroline Cabral Machado $^{\dagger}$
}

\begin{abstract}
Resumo
O trabalho elabora uma análise acerca dos efeitos da credibilidade monetária, da credibilidade fiscal e de outras variáveis expectacionais relacionadas ao ambiente macroeconômico sobre as expectativas dos empresários. Ademais, analisa a influência das expectativas dos empresários sobre as decisões de investimento e o nível de emprego no Brasil sob o regime de metas para inflação. Os resultados sugerem que o comprometimento das autoridades monetária e fiscal com seus objetivos exerce papel fundamental na formação das expectativas dos empresários com relação ao futuro da economia. Os achados também apontam que o investimento agregado e o emprego são afetados pelas expectativas empresariais.
\end{abstract}

Palavras-chave: Credibilidade; Expectativas; Dívida pública; Investimento; Emprego.

\begin{abstract}
The aim of this paper is to analyze the effects of monetary and fiscal credibility, and other expectational variables related to the macroeconomic environment regarding the expectations of entrepreneurs. It also examines the influence of entrepreneurs' expectations on investment decisions and employment in Brazil during the regime of inflation targeting. The results suggest that the commitment of both monetary and fiscal authorities with their goals plays a fundamental role in the formation of entrepreneurs' expectations about the future of the economy. Moreover, the findings also indicate that both aggregate investment and employment are affected by entrepreneurs' expectations.
\end{abstract}

Keywords: Credibility; Expectations; Public debt; Investment; Employment

JEL classification: E22, E24, E52, E58, E62.

DOI: http://dx.doi .org/10.1590/1413-8050/ea616

\footnotetext{
${ }^{*}$ Universidade Federal Fluminense; Pesquisador do CNPq. E-mail: gabrielmontesuff@yahoo.com.br

† Universidade Federal Fluminense. E-mail: carolcabralm@msn.com
} 


\section{Introdução}

Desde início da década de 1990, países vêm adotando o regime de metas para inflação com intuito de manter suas taxas de inflação baixas e estáveis e resguardar os ganhos obtidos com a estabilização dos preços. No Brasil, o regime de metas para inflação foi adotado em 1999. Desde então, a atuação da autoridade monetária passou a ter como principal objetivo manter a inflação e as expectativas de inflação convergindo para a meta estabelecida e, assim, conquistar credibilidade. Evidências empíricas relacionadas ao caso brasileiro apontam que a credibilidade assume papel central para o sucesso desse regime, sendo fundamental para a redução dos esforços da autoridade monetária em relação ao controle da inflação e, portanto, para a condução da política monetária (de Mendonça \& Souza 2009, Montes 2013, Montes \& Bastos 2014). Ao cumprir a meta estabelecida para a inflação e se mostrar com esse objetivo, o regime ganha credibilidade, a política monetária passa a ser conduzida de maneira menos abrupta e o ambiente macroeconômico fica mais estável. Por sua vez, um ambiente de estabilidade macroeconômica é fundamental para as decisões empresariais, as quais - em sua maioria - são baseadas em expectativas formadas acerca do ambiente econômico futuro.

Por seu turno, a condução da política fiscal e, consequentemente, o gerenciamento da dívida pública, desempenham importantes papéis no regime de metas para inflação. No estudo elaborado por de Mendonça (2004), é ressaltada a importância não apenas da condução da política monetária, mas também da política fiscal para o melhor desempenho do regime de metas para inflação. A ideia é que a utilização da política monetária, por meio da taxa básica de juros, para controlar a inflação e guiar as expectativas do público fica comprometida caso a dívida pública não esteja controlada. Nesse sentido, não somente as ações da autoridade monetária são importantes para o processo de formação de expectativas, mas também as ações da autoridade fiscal. Logo, além da credibilidade do regime de metas para inflação, a credibilidade fiscal também representa um importante elemento para o processo de formação de expectativas dos agentes.

O presente trabalho analisa a influência da credibilidade do regime de metas para inflação e a influência da credibilidade fiscal sobre as expectativas do empresário industrial e, por conseguinte, o efeito dessas expectativas sobre o investimento privado. $\mathrm{O}$ trabalho contribui com a literatura ao elaborar uma análise acerca dos efeitos da credibilidade monetária, da credibilidade fiscal e de outras variáveis expectacionais relacionadas ao ambiente macroeconômico sobre as expectativas dos empresários. Além disso, analisa o papel desempenhado pelas expectativas para as decisões de investimento e o nível de emprego no Brasil.

Portanto, este estudo tem como objetivos analisar empiricamente os seguintes aspectos: (i) a influência das credibilidades das políticas monetária e fiscal, ${ }^{1}$ em conjunto com outras variáveis expectacionais - relacionadas à inflação, ao crescimento do produto, à taxa Selic e à taxa de câmbio - sobre as expectativas dos empresários industriais, e (ii) a influência das expectativas dos empresários industriais sobre o investimento agregado e sobre o emprego.

\footnotetext{
${ }^{1}$ Para isso, o presente trabalho utiliza o índice de credibilidade para o regime de metas para inflação (ci), o qual foi proposto por de Mendonça (2007) e o índice de credibilidade fiscal (icf), o qual foi proposto por de Mendonça \& Machado (2013)
} 
A hipótese central a ser testada é a de que os comprometimentos das autoridades monetária e fiscal, com a manutenção de uma taxa de inflação baixa e estável e com a sustentabilidade da dívida pública respectivamente, contribuem para a formação de expectativas mais otimistas por parte dos empresários em relação ao estado da economia e também aos seus negócios, o que, por sua vez, terá impacto sobre o nível de investimento privado e sobre o nível de emprego.

A Figura 1 resume a análise feita no trabalho.

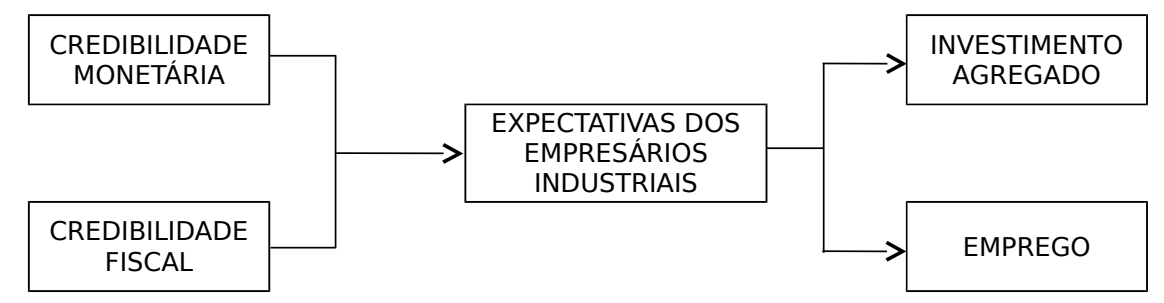

Figura 1: Esquema de análise

Para isso, além desta introdução, o trabalho apresenta as seguintes seções. A seção 2 apresenta uma breve resenha da literatura relacionada aos temas abordados. Na seção 3 é feita a análise empírica por meio de estimações por mínimos quadrados ordinários (MQO), pelo método generalizado dos momentos (GMM) e por meio de sistemas de equações utilizando GMM (systemGMM) referente ao período de janeiro de 2003 a março de 2013 para o caso brasileiro. A seção 4 apresenta as conclusões do trabalho.

\section{Resenha da literatura}

Os desdobramentos da literatura que trata da importância da credibilidade para o desempenho econômico se apoia no trabalho seminal de Kydland \& Prescott (1977). O trabalho de Kydland \& Prescott (1977) iniciou a análise da credibilidade da política monetária ressaltando o problema da inconsistência temporal. O argumento é que renegar compromissos estabelecidos em prol de resultados de curto prazo, os quais não se sustentam no longo prazo, em última instância, resultam em perda de credibilidade e construção de má reputação. Por conta disso, tecnologias de compromisso - tais como, bancos centrais independentes (Cukierman 1992), conservadorismo (Rogoff 1985) e contratos ótimos (Walsh 1995) - têm sido propostas com intuito de restringir as ações discricionárias dos policymakers. Isso porque, ações discricionárias que renegam compromissos assumidos resultam em inflação elevada e, por conseguinte, em baixa credibilidade.

O regime de metas para inflação representa uma tecnologia de compromisso que busca promover uma desinflação gradual nos preços, preservar os ganhos obtidos com a redução e estabilização da inflação e servir como âncora nominal para o processo de formação de expectativas dos agentes. De modo a servir como um guia para o processo de formação de expectativas dos agentes, confere importância à credibilidade e, portanto, impõe comprometimento à autoridade monetária com o seu principal objetivo de longo prazo.

Apesar de a credibilidade ser um elemento central para o sucesso do regime de metas para inflação, ela representa um conceito de difícil mensura- 
ção. Contudo, alguns economistas se empenharam em construir índices de credibilidade baseados na definição de credibilidade de Cukierman \& Meltzer (1986) e no argumento de Agénor \& Taylor (1992) de que séries de expectativas de inflação poderiam ser utilizadas para derivar esses índices - por exemplo, Cecchetti \& Krause (2002), de Mendonça (2007) e de Mendonça \& Souza (2009).

O trabalho elaborado por de Mendonça (2007) contribui com a literatura sobre mensuração da credibilidade da política monetária ao sugerir outra abordagem em relação à mensuração da credibilidade. Neste, um índice de credibilidade é construído com base na definição de Cukierman \& Meltzer (1986) para credibilidade e na ideia de Agénor \& Taylor $(1992,1993)$. Dando sequência, o estudo elaborado por de Mendonça \& Souza (2009) analisa, dentre uma série de índices de credibilidade e de reputação, quais deles são mais úteis na previsão de variações na taxa de juros a partir do ano 2000 para o caso brasileiro. $\mathrm{O}$ trabalho encontra evidências de que uma credibilidade mais elevada exige menores variações nas taxas de juros para o controle da inflação a partir da adoção do regime de metas para inflação, como também que, a credibilidade mais elevada conduz a taxa de juros a níveis menores. Esse resultado corrobora os argumentos de que uma política monetária crível exige menores esforços da autoridade monetária para o alcance da meta de inflação, pois terá uma capacidade maior de influênciar as expectativas dos agentes econômicos.

O trabalho de Montes \& Bastos (2011) investiga a influência da credibilidade do regime de metas para inflação sobre o comportamento da taxa nominal de juros de longo prazo (TNJLP) e, por conseguinte, sobre o spread da TNJLP. Foram feitas estimações para o spread compreendendo o período entre janeiro de 2000 e setembro de 2009. As evidências empíricas encontradas sugerem que os ganhos de credibilidade promoveram a redução do spread e a suavização da curva de juros. Montes \& Bastos (2013) buscam analisar a influência das variáveis macroeconômicas e das políticas monetária e fiscal sobre as expectativas e confiança dos empresários no Brasil. Para isso, é feita uma análise econométrica para o período entre o primeiro trimestre de $2000 \mathrm{e}$ o segundo trimestre de 2010. Os resultados indicam que um aumento na credibilidade cria um ambiente mais estável, contribuindo positivamente para aumentar a confiança dos empresários na economia e nos seus negócios e, por conseguinte, sendo capaz de afetar a atividade econômica (medida pela produção industrial).

No estudo de Montes (2013) é feita uma análise para os efeitos da credibilidade do banco central, após a adoção do regime de metas para inflação no Brasil, sobre a condução da política monetária e seus canais de transmissão, com ênfase no canal das expectativas. O canal das expectativas é analisado por meio das expectativas dos empresários e o efeito dessas expectativas sobre os gastos com investimentos. A análise econométrica é feita para o período compreendido entre o quarto trimestre de 2001 e o segundo trimestre de 2011. Foram encontradas evidências de que os ganhos de credibilidade auxiliam na obtenção de um ambiente macroeconômico mais estável, o que afeta positivamente as expectativas dos empresários, servindo como um estímulo ao aumento de seus investimentos. Dessa forma, a ancoragem das expectativas de inflação e, portanto, os ganhos de credibilidade servem como estímulo ao aumento dos investimentos na economia.

De acordo com Christiano \& Fitzgerald (2000), muitos trabalhos mostram que uma política monetária baseada em regras resulta em substanciais ganhos 
de bem-estar, entretanto, os trabalhos costumam ignorar o papel da política fiscal e suas implicações. Segundo os autores, alguns economistas começaram a repensar se um banco central comprometido com a busca pela estabilidade de preços seria suficiente para garantir o alcance deste objetivo. Para esses economistas é necessário não apenas uma política monetária adequada, mas também uma política fiscal. Isto é, apesar do papel central da credibilidade da política monetária, a credibilidade fiscal também é de extrema importância para o controle da inflação.

Entre os trabalhos a respeito do papel da política fiscal na obtenção dos objetivos da política monetária para o caso brasileiro, além do trabalho elaborado por de Mendonça (2004), encontram-se os trabalhos de: Pires (2006), o qual visa analisar a credibilidade da política fiscal brasileira a partir de dados a respeito da expectativa de superávit primário e da expectativa da dívida líquida do setor público; o trabalho de de Mendonça \& da Silva (2008), o qual mostra que o gerenciamento da dívida pública está diretamente relacionado à aquisição de credibilidade da política econômica e sugere que uma dívida pública menos indexada à taxa Selic faz com que a autoridade monetária tenha maior liberdade na busca pela estabilidade de preços, resultando assim em maior credibilidade; e o trabalho de Moreira \& Rocha (2011), o qual faz uma análise em painel acerca do papel da política fiscal sobre as taxas de juros de 18 países emergentes, incluindo o Brasil, para o período de 1996 a 2008, obtendo resultados que indicam que não é possível rejeitar a hipótese de que uma política baseada na austeridade fiscal diminui a taxa de juros doméstica.

O trabalho elaborado por de Mendonça \& Machado (2013) propõe um indicador de credibilidade fiscal e busca evidências empíricas sobre os efeitos das principais variáveis relacionadas à estrutura de composição da dívida pública e também o efeito desta estrutura sobre a razão dívida/PIB, para o período compreendido entre dezembro de 2003 e julho de 2011. A análise se baseia em estimações pelos métodos MQO e GMM. Os resultados indicam que o compromisso com a dívida pública aumenta a credibilidade fiscal, sendo esta por sua vez importante para o gerenciamento da dívida pública. Dessa forma, aponta para a importância do governo adotar uma política fiscal crível. Em particular, os ganhos de credibilidade fiscal permitem ao governo adotar estratégias de recomposição da dívida pública.

No tocante ao investimento agregado, este é essencialmente um processo forward-looking, no qual os ganhos dos agentes no futuro refletirão as decisões de investimentos que estes tomaram em um período anterior. Por não ter acesso a todas as informações para períodos à frente devido às incertezas do ambiente econômico, os agentes tomam suas decisões baseados em expectativas que consideram as informações disponíveis no presente, para períodos posteriores. Desta forma, o regime de metas para inflação contribui para a formação das expectativas dos agentes à medida que adquire credibilidade ao promover um ambiente macroeconômico estável, permitindo assim uma maior previsibilidade com relação ao futuro da economia aos agentes. Essa maior previsibilidade, por sua vez, permite um aumento do investimento por reduzir os riscos associados à incerteza com relação ao futuro.

Uma autoridade monetária comprometida com a manutenção de uma taxa de inflação baixa e estável estaria, então, contribuindo para o aumento dos investimentos privados por possibilitar um maior horizonte de planejamento necessário aos investimentos. Diversos trabalhos se propõem a identificar os principais determinantes do investimento e, em geral, todos apontam que 
uma dessas variáveis relevantes seria a instabilidade econômica. Isto é, existiria uma relação negativa entre a instabilidade e o investimento, o que demonstraria a importância de uma política orientada no sentido de manter um ambiente macroeconômico estável, favorável à tomada de decisões.

O trabalho de Grenne \& Villanueva (1991) encontra evidências de que a instabilidade macroeconômica, representada pela elevada taxa de inflação, exerce efeitos negativos sobre o investimento privado, por aumentar os riscos associados aos investimentos de longo prazo.

De acordo com o trabalho de Pindyck \& Solimano (1993), o nível e a variância da inflação devem ser os melhores indicadores de instabilidade econômica, esta, por sua vez, estando associada com baixas taxas de formação de capital. A partir da análise de cinco países da América Latina, dentre eles o Brasil, para o período de 1960 e 1990, os autores mostram a importância da taxa de inflação para a determinação do investimento privado, sugerindo que, por esse motivo, o controle da inflação deve ser o objetivo primordial da política econômica.

O trabalho de Melo \& Rodrigues Jr (1998) busca identificar empiricamente os principais determinantes do investimento privado no Brasil para o período compreendido entre 1970 e 1995 . Os resultados apontam o significativo impacto negativo da instabilidade econômica, sendo utilizada na análise a taxa de inflação como proxy para instabilidade. O efeito negativo encontrado da taxa de inflação foi inclusive maior que o efeito negativo do nível da taxa de juros. Dessa forma, aumentos na instabilidade e na incerteza poderiam fazer com que os agentes adiassem seus planos de investimento, desestimulando o investimento privado. O trabalho de Ribeiro \& Teixeira (2001) busca responder a mesma pergunta e encontra como resultado relevante a influência negativa das incertezas sobre o investimento privado no Brasil.

O artigo de Luporini \& Alves (2010) se propõe a analisar os principais determinantes do investimento privado no Brasil para o período entre $1970 \mathrm{e}$ 2005. Foi incluída nas estimações uma variável para a instabilidade econômica, que utiliza a taxa de inflação, a taxa de juros real e a taxa de câmbio, além de uma dummy para capturar os efeitos da instabilidade política. Os resultados indicam a importância de um ambiente macroeconômico estável e a necessidade de implementação de políticas consistentes ao longo do tempo como forma de incentivo ao investimento.

O artigo elaborado por de Mendonça \& Lima (2011) estima o impacto de variáveis macroeconômicas no investimento privado sob o regime de metas para inflação para a economia brasileira no período de janeiro de 2000 a setembro de 2009. Com base nas evidências encontradas pelos autores, os resultados sugerem que, dentre as variáveis importantes para promover o investimento privado, a credibilidade desempenha importante papel no desenvolvimento de um ambiente macroeconômico estável, e, portanto, para o investimento privado. 


\section{Análise empírica}

\subsection{Dados}

O período analisado compreende o primeiro trimestre de 2003 até o primeiro trimestre de $2013 .^{2}$ As séries (trimestrais) utilizadas neste estudo são:

Índice de expectativas do empresário industrial $(i e e)^{3}$ Esse índice expressa as expectativas dos empresários industriais acerca da economia e de seus negócios para os 6 meses seguintes. O índice varia entre 0 e 100, em que 0 indica extrema falta de confiança nas expectativas e 100 extrema confiança nas expectativas. Dessa forma, quanto maior o índice, melhores são as expectativas dos empresários em relação à economia e aos seus negócios.

Formação bruta de capital fixo $(g f c f)^{4}$ A formação bruta de capital fixo mede o quanto a indústria aumentou seus bens de capital e indica, dessa forma, se a capacidade produtiva do país está crescendo. A hipótese testada é a de que um aumento no índice de expectativas do empresário industrial resulte em aumento da capacidade produtiva do país.

Emprego (emp $)^{5}$ Essa variável expressa o total de pessoas empregadas na indústria. Expectativas otimistas dos empresários em relação à economia e aos seus negócios deve estimular a produção, aumentando a demanda por mão de obra e, com isso, aumentando o número de pessoas empregadas.

Índice de confiança do empresário industrial (ice $)^{6}$ Essa variável expressa a percepção dos empresários acerca das condições atuais da economia e de deus negócios com base nos 6 meses anteriores. O índice varia entre 0 e 100, em que 0 indica extrema falta de confiança e 100 extrema confiança. Dessa forma, um valor mais elevado para esse índice demonstra uma maior confiança dos empresários para seus negócios. A hipótese testada é a de que um aumento na confiança do empresário industrial em relação às condições atuais da economia e de seus negócios resulte em melhora das expectativas.

\footnotetext{
${ }^{2}$ A justificativa para utilização deste período se baseia na disponibilidade das séries no site do Banco Central do Brasil (BCB).

${ }^{3}$ Série 7343 - Índice de confiança do empresário - Expectativas - disponível no site do BCB. O índice é calculado pela Confederação Nacional da Indústria (CNI).

${ }^{4}$ Série Capital fixo - formação bruta - consumo aparente de máquinas — índice encadeado (média $1996=100$ ) — disponível no site IPEADATA. Índice elaborado pelo Instituto de Pesquisa Econômica Aplicada (IPEA), construído a partir da produção de bens de capital da Pesquisa Industrial Mensal - Produção Física do IBGE e índices de quantum das exportações e importações de bens de capital da Funcex. Série ajustada à variação real anual da série máquinas e equipamentos do Sistema de Contas Nacionais (IBGE).

${ }^{5}$ Série Pessoal empregado na indústria: índice dessazonalizado (média $2006=100$ ) — disponível no site IPEADATA. A série é calculada pela Confederação Nacional da Indústria (CNI).

${ }^{6}$ Série 7342 - Índice de confiança do empresário - condições reais - disponível no site do BCB. O índice é calculado pela Confederação Nacional da Indústria (CNI).

${ }^{7}$ Série Expectativa média de inflação — IPCA — taxa anualizada para os próximos doze meses - disponível no site do BCB. Os dados são obtidos de pesquisas (entrevistas) realizadas com especialistas em previsão de mercado (forecasters) sobre suas expectativas de inflação; ou seja, são utilizados os dados da survey do Banco Central do Brasil (BCB) a fim de obter as expectativas de inflação do mercado.
} 
Expectativa de inflação $(\exp i n f)^{7}$ Essa série expressa as expectativas dos agentes com relação à inflação para os 12 meses seguintes. A hipótese testada é a de que um aumento na variabilidade da inflação esperada para os próximos doze meses aumente as incertezas e, portanto, resulte em piora das expectativas do empresário industrial.

Expectativa para produção industrial $\left(y_{e}\right)^{8}$ Essa série expressa as expectativas dos agentes com relação ao crescimento do produto para os 12 meses seguintes. A hipótese testada é a de que um crescimento mais acentuado da produção eleve as expectativas do empresário industrial, devido à perspectiva de aumento dos negócios e da atividade econômica.

Expectativa para taxa Selic $\left(\text { selic }_{e}\right)^{9}$ Essa série expressa o que os agentes esperam para a trajetória da taxa Selic para os 12 meses seguintes. A taxa Selic é o principal instrumento de política monetária no Brasil, dessa forma, a hipótese testada é a de que uma expectativa de alta para essa taxa indicaria um aperto monetário no futuro, resultando, assim, em deterioração das expectativas do empresário industrial.

Taxa de câmbio (cambio $)^{10}$ A hipótese testada é a de que depreciações cambiais tornam as importações de bens de capital mais caras, sendo esperada, portanto, uma relação inversa entre taxa de câmbio e a ampliação da capacidade produtiva.

Expectativa para taxa de câmbio $\left(\text { cambio }_{e}\right)^{11}$ Essa série expressa a expectativa para a taxa de câmbio para os 12 meses seguintes. A teoria econômica sugere que depreciações cambiais estimulam as exportações, e assim a atividade econômica, favorecendo os negócios. Dessa forma, é testada a hipótese de relação positiva entre a expectativa formada para a taxa de câmbio e o índice de expectativas do empresário industrial.

Índice de credibilidade do regime de metas de inflação $(c i)^{12}$ Esta série é calculada com base no índice proposto por de Mendonça (2007). O índice assume valor igual a 1 quando a inflação anual esperada $(E(\pi))$ for igual a meta de inflação $\left(\pi_{m}\right)$ e decresce a medida que as expectativas para a inflação se desviam da meta anunciada. O índice assume valores entre 0 e 1 quando a expectativa de inflação se situa dentro dos limites mínimo

\footnotetext{
${ }^{8}$ Série Produção industrial — variação \% — Média disponível no site do BCB. Dados obtidos de pesquisas (entrevistas) realizadas com especialistas em previsão de mercado (forecasters) sobre suas expectativas para produção industrial; ou seja, são utilizados os dados da survey do Banco Central do Brasil (BCB).

${ }^{9}$ Série Meta Selic-Over - \% a.a. - Média disponível no site do BCB. Dados obtidos de pesquisas realizadas com especialistas em previsão de mercado sobre suas expectativas para taxa Selic; ou seja, são utilizados os dados da survey do Banco Central do Brasil (BCB).

${ }^{10}$ Esta série é calculada por meio da média entre as séries 3695 "Taxa de câmbio — Livre Dólar americano (compra) — Fim de período - mensal" e 3696 "Taxa de câmbio — Livre Dólar americano (venda) - Fim de período - mensal”, ambas disponíveis no site do BCB. A fonte das séries é o Sistema de Informações Banco Central — Transação PTAX800.

${ }^{11}$ Série Expectativas de mercado - Taxa de câmbio - R/US - Média - disponível no site do BCB. Dados obtidos de pesquisas (entrevistas) realizadas com especialistas em previsão de mercado (forecasters) sobre suas expectativas para a taxa de câmbio; ou seja, são os dados da survey do Banco Central do Brasil (BCB).

${ }^{12}$ Pelo fato da meta de inflação ser estabelecida para um determinado ano, foi utilizado o dado de expectativa de inflação acumulada para os próximos 12 meses, divulgado no site do BCB.
} 
e máximo $\left(\pi_{t}^{*}\right)$ estabelecidos para cada ano, e caso exceda um desses limites, assume valor igual a 0 . É testada a hipótese de que um aumento na credibilidade aumente as expectativas dos empresários por criar um ambiente econômico mais estável. O índice é calculado da seguinte maneira:

$$
c i=\left\{\begin{array}{l}
1 \text { se } E(\pi)=\pi_{t}^{m} \\
1-\frac{1}{\pi_{t}^{*}-\pi_{t}^{m}}\left[E(\pi)-\pi_{m}^{t}\right] \text { se } \pi_{t M i n}^{*}<E(\pi)<\text { se } \pi_{t M a x}^{*} \\
0 \text { se } E(\pi)>\text { se } \pi_{t M a x}^{*} \text { ou } E(\pi) \leq \text { se } \pi_{t M i n}^{*}
\end{array}\right\}
$$

Índice de credibilidade fiscal $(i c f)^{13}$ Série calculada com base no índice proposto por de Mendonça e Machado (2013). O índice assume valor igual a 1 quando a expectativa do mercado sobre a dívida pública para os 12 meses seguintes é menor que o limite inferior $(40 \%),{ }^{14}$ pois nesse caso não há risco de desequilíbrio fiscal e assume valor igual a 0 quando a expectativa do mercado para os 12 meses seguintes é maior que o limite superior $(60 \%),{ }^{15}$ pois nesse caso há elevada probabilidade de ocorrência de um desequilíbrio fiscal. Quando a expectativa do mercado se situa entre os limites inferior e superior, o índice assume valores entre 0 e 1 e, nesse caso, o risco de desequilíbrio fiscal é crescente à medida que se aproxima do limite superior. Uma credibilidade fiscal alta indicaria que o governo está comprometido com a manutenção da trajetória sustentável da dívida pública, sendo esperada uma relação positiva entre essa variável e o índice de expectativas do empresário industrial. Portanto, a hipótese testada é de uma relação positiva entre o índice de credibilidade fiscal e as expectativas dos empresários. O índice é calculado da seguinte maneira:

$$
i c f=\left\{\begin{array}{l}
1 \text { se } E_{t}\left(d e b t_{t+12}\right) \leq d e b t^{M i n} \\
1-\left[\frac{E_{t}\left(d e b t_{t+12}\right)-d e b t^{M i n}}{d e b t_{t}^{M a x}-d e b t_{t}^{M i n}}\right] \text { se } \pi_{t M i n}^{*}<E_{t}\left(d e b t_{t+12}\right)<d e b t^{M a x} \\
0 \text { se } E_{t}\left(d e b t_{t+12}\right) \geq d e b t^{M a x}
\end{array}\right\}
$$

Hiato do produto (hiato) Essa variável expressa a influência dos ciclos na economia, sendo a diferença entre o produto efetivo e sua tendência de longo prazo. O produto efetivo é o log do produto interno bruto ${ }^{16}$ des-

\footnotetext{
${ }^{13}$ Seguindo de Mendonça \& Machado (2013), para a elaboração deste índice foi utilizada a série Expectativas de mercado - Fiscal — Média — Dívida líquida do setor público — disponível no site do BCB. Dados obtidos de pesquisas (entrevistas) realizadas com especialistas em previsão de mercado (forecasters) sobre suas expectativas para a dívida líquida do setor público; ou seja, são os dados da survey do Banco Central do Brasil (BCB).

${ }^{14}$ Meta de longo prazo, de acordo com cálculos do IMF (2002), que não deve ser violada pelas economias emergentes.

${ }^{15}$ Estabelecido pelo Tratado de Maastricht.

${ }^{16}$ Série 4380 - PIB mensal - Valores correntes (R \$ milhões) - disponível no site do BCB. O PIB mensal é um indicador mensal produzido pelo Banco Central do Brasil. Como informa o próprio $\mathrm{BCB}$, não se trata de cálculo do PIB a partir de informações primárias, mas apenas de uma estimativa que é feita via interpolação dos valores trimestrais já divulgados ou dos projetados.
} 
sazonalizado (método census X12) e deflacionado pelo IPCA, ${ }^{17}$ e a tendência de longo prazo do produto foi calculada utilizando-se o filtro Hodrick-Prescott. Assim, a hipótese testada é a de que um aumento (redução) no valor dessa série aumente (reduza) a formação bruta de capital fixo, pois indicaria que a atividade econômica está aquecida (desaquecida).

Crédito em relação ao PIB (credito) ${ }^{18}$ O crédito é uma variável importante para as decisões de investimento. A hipótese testada é a de que um aumento na oferta de crédito estimule o nível de investimento, elevando a formação bruta de capital fixo.

Taxa de juros real $\left(i r_{\text {real }}\right)^{19}$ Essa série representa a taxa de juros descontada da inflação. Logo, espera-se que um aumento nessa taxa reduza os investimentos, pois o custo do capital estará mais elevado. A hipótese testada é de uma relação negativa com a formação bruta de capital fixo.

Salário real $\left(\text { sal }_{\text {real }}\right)^{20}$ Essa variável representa o salário nominal descontado a inflação, medida pelo INPC (Índice Nacional de Preços ao Consumidor) e está sendo usada como uma proxy para o custo da mão de obra. Dessa forma, é esperada uma relação negativa entre o salário real e o nível de empregos, uma vez que um salário mais elevado desestimula as contratações.

A Figura 2 apresenta os gráficos com a evolução no tempo das principais variáveis utilizadas no trabalho.

\subsection{Metodologia}

A análise empírica foi conduzida utilizando Mínimos Quadrados Ordinários (MQO), o Método Generalizado dos Momentos (GMM) e sistema de equações por GMM (GMM system). As estatísticas $t$ relatadas nas estimativas por MQO são baseadas no estimador de Newey \& West (1987), o qual é consistente com a presença de heteroscedasticidade e autocorrelação de formas desconhecidas. A razão para a utilização do GMM se deve ao fato de as estimativas por MQO apresentarem problemas de autocorrelação e heteroscedasticidade de forma desconhecida ou endogeneidades e não linearidades, o que é comum em séries temporais macroeconômicas; esse método oferece estimadores consistentes para a regressão (Hansen 1982). Como apontado por Wooldridge (2001, p.95), "to obtain a more efficient estimator than two-stage least squares (or ordinary least squares), one must have overriding restrictions". A matriz de ponderação na equação foi escolhida para permitir que as estimativas por GMM

\footnotetext{
${ }^{17}$ Série IPCA geral índice dez.1993 $=100$ - disponível no site IPEADATA. O índice foi elaborado pelo Instituto Brasileiro de Geografia e Estatística, Sistema Nacional de Índices de Preços ao Consumidor (IBGE/SNIPC).

${ }^{18}$ Série 17473 - Razão crédito/PIB - disponível no site do BCB. A série é elaborada pelo Banco Central do Brasil.

${ }^{19}$ Série calculada por meio da diferença entre as séries 4189 "Taxa de juros" — Selic acumulada no mês anualizada e "Expectativa média de Inflação — IPCA — taxa acumulada para os próximos doze meses".

${ }^{20}$ Série Salário real — médio — indústria — índice (média $2006=100$ ) - SP — disponível no site IPEADATA.
} 
$\mathrm{Cl}$

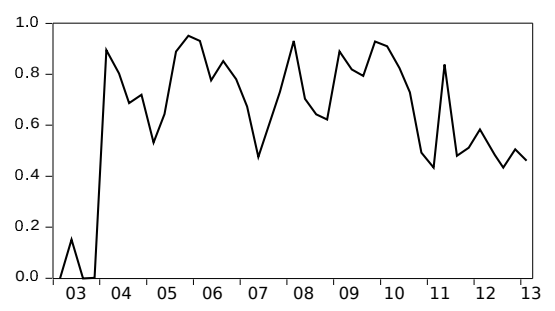

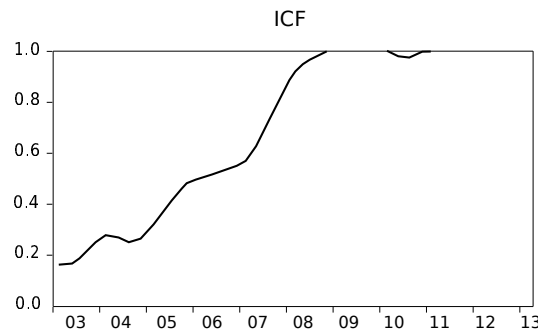

IEE

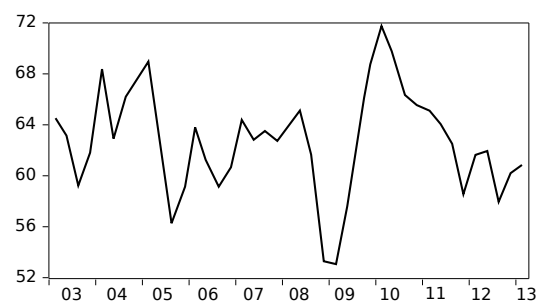

GFCF

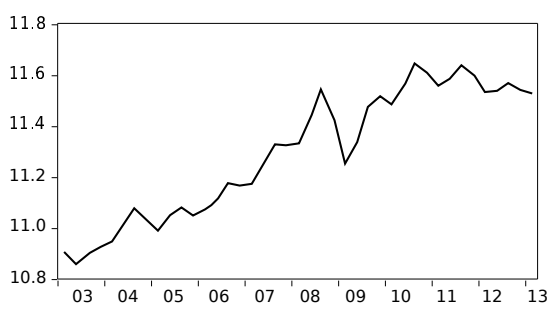

EMP

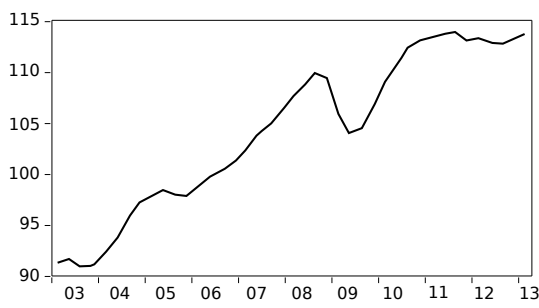

OBS: Essa figura foi elaborada no software Eviews 7.0.

Figura 2: Evolução das principais variáveis

sejam robustas, considerando a possível presença de heterocedasticidade e autocorreção de formas desconhecidas. Em relação à técnica GMM, Cragg (1983) indicou que a análise de sobreidentificação tem um papel importante na seleção das variáveis instrumentais para melhorar a eficiência dos estimadores. Sendo assim, o teste $J$ padrão foi realizado (Hansen 1982). Todas as estimações foram feitas pelo software Eviews 7.0.

No tocante às especificações de todas as equações, cabe esclarecer que a escolha dos lags foi determinada por meio da metodologia "geral para o específico", utilizando os critérios de informação tradicionalmente aplicados, além do princípio da parcimônia e com base na teoria econômica. Ou seja, essa metodologia leva em consideração não somente a significância estatística dos parâmetros, mas também os testes de diagnósticos, com intuito de assegurar que o modelo escolhido apresenta poder explicativo.

Por se tratar de análise utilizando séries temporais, uma primeira condição a ser verificada, antes de serem feitas as estimações, é testar se as séries são estacionárias. Para isso foi aplicado o teste Kwiatkowski-Phillips-Schmidt-Shin (KPSS). A vantagem desse teste resulta do baixo poder de testes convencionais, que tendem a não rejeitar a hipótese nula demasiadas vezes (Franses \& Haldrup 1994, Cati et al. 1999). Ademais, Kwiatkowski et al. (1992) argumentam que o teste KPSS pode distinguir séries que aparentam ser estacionárias, séries que aparentam ter uma raiz unitária e séries para as quais os dados não são suficientemente informativos para ter a certeza se são estacionárias ou in- 
tegradas - como é o caso de séries com curta periodicidade (os resultados do teste estão na Tabela A.1 do Apêndice). Pelo fato das séries de expectativa de inflação (expinf) e de salário real $\left(s a l_{\text {real }}\right)$ serem $I(1)$, as estimações serão feitas com as variáveis em primeira diferença (ou seja, $d_{\text {expinf }}$ e $d_{\text {sal }}$ real ) de modo a ser evitado o problema de regressão espúria.

\subsection{Estimações para os determinantes das expectativas do empresário industrial}

Com intuito de analisar a influência que exerce a credibilidade do regime de metas para inflação e a credibilidade fiscal sobre o índice de expectativas do empresário industrial, a seguinte equação (1) foi estimada:

$$
\begin{aligned}
\text { iee }= & \beta_{1}+\beta_{2} \text { ice }_{-1}+\beta_{3} d_{\text {expinf }-3}+\beta_{4} y_{e-1}+\beta_{5} \text { selic }_{e-1}+ \\
& \beta_{6} \text { cambio }_{e-2}+\beta_{7} c i_{-2}+\beta_{8} i c f_{-3}+\epsilon
\end{aligned}
$$

em que $\epsilon$ é o termo de erro. As derivadas parciais abaixo expressam as relações esperadas e, portanto, as hipóteses testadas:

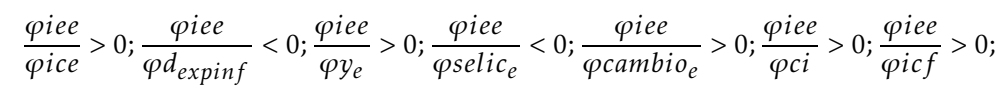

As Tabelas 1 e 2 mostram as estimações para a equação (1). ${ }^{21}$

As estimações mostram que o efeito do ice sobre o iee é positivo e possui significância estatística. Desta forma, a evidência encontrada revela que uma visão mais otimista dos empresários acerca da economia e de seus negócios irá auxiliar na formação de expectativas mais otimistas acerca da economia e de seus negócios para o futuro.

O efeito estimado da variável $d_{\text {expinf }}$ é negativo e possui significância estatística. Assim, as evidências sugerem que expectativas de inflação mais elevadas estão associadas à expectativa de um ambiente macroeconômico mais incerto, sendo, portanto, menos favorável aos negócios.

As estimativas para a variável $y_{e}$ apresentaram coeficientes positivos e significância estatística. As evidências sugerem que uma expectativa maior para o produto é favorável à formação de expectativas otimistas dos empresários.

As estimativas para a variável selic $_{e}$ apresentaram coeficientes negativos e significância estatística. Uma expectativa de taxa Selic mais elevada no futuro estimula a formação de expectativas pessimistas dos empresários em relação à economia e aos seus negócios.

O efeito estimado para a variável cambio $_{e}$ apresentou sinal positivo e significância estatística em todas as especificações. Uma expectativa de desvalorização cambial torna mais otimista a expectativa dos empresários industriais, pois com a taxa de câmbio mais desvalorizada no futuro espera-se que as exportações aumentem.

A variável $c i$ apresentou coeficientes estimados positivos e significância estatística. Uma maior credibilidade significa que o processo de ancoragem das expectativas de inflação em relação à meta de inflação está mais forte, o que gera um ambiente mais favorável aos negócios por permitir aos agentes uma

\footnotetext{
${ }^{21}$ As estimações por GMM utilizaram as seguintes variáveis instrumentais: $i e e_{-1}, i c e_{-2}, i c e_{-3}$, $i c e_{-4}, d_{\text {expinf }-4}, y_{e-2}, y_{e-3}, y_{e-4}$, selic $_{e-2}$, selic $_{e-3}$, cambio $_{e-3}$, cambio $_{e-4}$, ci $_{-3}, i c f_{-4}$.
} 
Tabela 1: Estimações MQO (iee)

\begin{tabular}{|c|c|c|c|c|c|c|}
\hline $\begin{array}{l}\text { Variável dependente: } \\
\text { iee }\end{array}$ & & & & MQO & & \\
\hline Variáveis Explicativas & sp.1 & sp.2 & sp.3 & sp.4 & sp.5 & sp.6 \\
\hline constante & $\begin{array}{l}38,0872^{* * * *}[7,6551] \\
\quad(4,9753)\end{array}$ & $\begin{array}{l}41,0180^{* * *}[7,1336] \\
(5,7499)\end{array}$ & $\begin{array}{l}37,5330^{* * *}[6,9001] \\
(5,4394)\end{array}$ & $\begin{array}{c}36,5927^{* * *}[7,0653] \\
(5,1791)\end{array}$ & $\begin{array}{c}24,5421^{* *} \\
(10,153)\end{array}$ & $\begin{array}{c}20,9875^{* *} \\
(9,5265)\end{array}[2,2030]$ \\
\hline$i_{c e} e_{-1}$ & $\underset{(0,0934)}{0,1960^{* *}}[2,0980]$ & $\underset{(0,0952)}{0,2149^{* *}}[2,2571]$ & $\underset{(0,0874)}{0,2211^{* *}}[2,5290]$ & $\underset{(0,0846)}{0,2566^{* * * *}}[3,0316]$ & $\underset{(0,0896)}{0,2603^{* * *}[2,9059]}$ & $\underset{(0,0853)}{0,3073^{* * *}[3,6035]}$ \\
\hline$d_{\text {expinf }}-3$ & $\begin{array}{c}-2,9346^{* * * *}[-3,4151] \\
(0,8593)\end{array}$ & $\begin{array}{l}-3,1130^{* * *}[-3,5509] \\
\quad(0,8766)\end{array}$ & $\begin{array}{r}-1,6588^{*} \\
(0,9746)\end{array}$ & $\underset{(1,0454)}{-2,6879^{* *}}[-2,5711]$ & $\begin{array}{r}-1,9127^{*} \\
(0,9702)\end{array}$ & $\begin{array}{l}-3,1065^{* * *}[-3,0305] \\
(1,0250)\end{array}$ \\
\hline$y_{e-1}$ & $\underset{(1,1151)}{3,2469^{* * *}}[2,9116]$ & $\underset{(1,1407)}{3,0004^{* *}}[2,6302]$ & $\underset{(1,0493)}{3,1879^{* * *}[3,0379]}$ & $\underset{(1,0598)}{2,4206^{* *}}[2,2839]$ & $\underset{(1,0641)}{2,7780^{* *}}[2,6105]$ & $\underset{(1,0587)}{1,8453^{*}}[1,7429]$ \\
\hline selic $_{e-1}$ & & $\underset{(0,2281)}{-0,2316} \quad[-1,0154]$ & $\underset{(0,2994)}{-0,7974^{* *}}[-2,6635]$ & $\begin{array}{c}-0,8896^{* * *}[-3,0960] \\
(0,2873)\end{array}$ & $\begin{array}{r}-0,6145^{*} \\
(0,3177)\end{array} \quad[-1,9341]$ & $\underset{(0,2958)}{-0,6817^{* *}}[-2,3041]$ \\
\hline cambio $_{e-2}$ & & & $\underset{(1,608355)}{4,25194^{* *}}[2,643658]$ & $\underset{(1,525864)}{4,207938^{* * *}}[2,757741]$ & $\underset{(2,393675)}{6,959945^{* * *}[2,90764]}$ & $\begin{array}{c}7,433934^{* * *}[3,33678] \\
\underset{(2,227876)}{ }\end{array}$ \\
\hline$c i_{-2}$ & & & & $\begin{array}{c}5,330474^{* *} \\
(2,527212)\end{array}[2,109231]$ & & $\underset{(2,441328)}{5,929531^{* *}}[2,428813]$ \\
\hline$i c f_{-3}$ & & & & & $\underset{(4,299551)}{6,464504} \quad[1,50353]$ & $\underset{(4,019357)}{7,712848^{*}}[1,918926]$ \\
\hline Adjusted $R^{2}$ & 0,434 & 0,435 & 0,524 & 0,571 & 0,619 & 0,683 \\
\hline F-statistic (p-valor) & 0,000 & 0,000 & 0,000 & 0,000 & 0,000 & 0,000 \\
\hline $\begin{array}{l}\text { Ramsey - RESET (1)(p- } \\
\text { value) }\end{array}$ & 0,840 & 0,786 & 0,385 & 0,880 & 0,234 & 0,487 \\
\hline Jarque-Bera (p-value) & 0,884 & 0,996 & 0,574 & 0,621 & 0,344 & 0,685 \\
\hline $\mathrm{ARCH}(1)(\mathrm{p}$-value $)$ & 0,692 & 0,437 & 0,657 & 0,982 & 0,639 & 0,908 \\
\hline $\mathrm{ARCH}(2)(\mathrm{p}$-value) & 0,912 & 0,670 & 0,764 & 0,788 & 0,754 & 0,980 \\
\hline ARCH (4)(p-value) & 0,316 & 0,350 & 0,805 & 0,861 & 0,926 & 1,000 \\
\hline $\mathrm{ARCH}(8)(\mathrm{p}$-value $)$ & 0,685 & 0,697 & 0,852 & 0,765 & 0,751 & 0,882 \\
\hline $\mathrm{LM}(1)(\mathrm{p}$-value $)$ & 0,082 & 0,142 & 0,474 & 0,604 & 0,491 & 0,772 \\
\hline $\mathrm{LM}(2)(\mathrm{p}$-value $)$ & 0,086 & 0,136 & 0,197 & 0,265 & 0,132 & 0,135 \\
\hline LM(3)(p-value) & 0,163 & 0,229 & 0,249 & 0,439 & 0,087 & 0,229 \\
\hline LM(4)(p-value) & 0,283 & 0,361 & 0,303 & 0,229 & 0,167 & 0,307 \\
\hline
\end{tabular}


Tabela 2: Estimações GMM (iee)

\begin{tabular}{|c|c|c|c|c|c|c|}
\hline $\begin{array}{l}\text { Variável dependente: } \\
\text { iee }\end{array}$ & & & GM & MM & & \\
\hline Variáveis Explicativas & sp.1 & sp.2 & sp.3 & sp.4 & sp.5 & sp.6 \\
\hline constante & $\begin{array}{l}31,0603^{* * *}[17,338] \\
(1,7914)\end{array}$ & $\begin{array}{l}34,5779^{* * *}[11,017] \\
(3,1384)\end{array}$ & $\begin{array}{l}32,6399^{* * *}[8,1487] \\
\quad(4,0055)\end{array}$ & $\begin{array}{l}31,8608^{* * *}[9,3816] \\
(3,3960)\end{array}$ & $\begin{array}{c}27,2796^{* * *}[4,4617] \\
(6,1140)\end{array}$ & $\begin{array}{l}25,1074^{* * *}[5,3388] \\
\quad(4,7027)\end{array}$ \\
\hline$i^{i c e_{-1}}$ & $\underset{(0,0745)}{0,0818}[1,0984]$ & $\underset{(0,0879)}{0,1212}[1,378]$ & $\underset{(0,0688)}{0,1010}[1,4674]$ & $\underset{(0,0749)}{0,1735^{* *}}[2,3153]$ & $\underset{(0,1044)}{0,1607}[1,5384]$ & $\underset{(0,0772)}{0,2525^{* * *}[3,2684]}$ \\
\hline$d_{\text {expinf }_{-3}}$ & $\underset{(0,8103)}{-4,5491^{* * * *}}[-5,6141]$ & $\begin{array}{l}-4,6629^{* * *}[-5,4826] \\
\quad(0,8504)\end{array}$ & $\begin{array}{r}-2,3853^{*} \\
(1,2092)\end{array}$ & $\underset{(1,1497)}{-2,7908^{* *}}[-2,4273]$ & $\underset{(1,6268)}{-3,0818^{*}}[-1,8942]$ & $\underset{(1,3857)}{-3,7567^{* *}}[-2,7108]$ \\
\hline$y_{e-1}$ & $\underset{(0,8789)}{6,1117^{* * * *}}[6,9531]$ & $\underset{(1,0423)}{5,6214^{* * *}[5,3928]}$ & $\underset{(0,8200)}{5,7832^{* * *}}[7,0523]$ & $\underset{(1,0208)}{4,7131^{* * * *}}[4,6169]$ & $\underset{(1,1923)}{5,1517^{* * * *}}[4,3206]$ & $\underset{(1,0835)}{3,5953^{* * *}[3,3179]}$ \\
\hline selic $_{e-1}$ & & $\underset{(0,1447)}{-0,2854^{*}} \quad[-1,9721]$ & $\begin{array}{l}-0,6353^{* * *}[-3,1837] \\
\quad(0,1995)\end{array}$ & $\begin{array}{l}-0,7403^{* * * *}[-4,3968] \\
\quad(0,1683)\end{array}$ & $\underset{(0,2003)}{-0,5546^{* * *}[-2,7691]}$ & $\underset{(0,1544)}{-0,6797^{* * *}}[-4,4020]$ \\
\hline cambio $_{e-2}$ & & & $\begin{array}{r}3,0523^{* *} \\
(1,3520)\end{array}[2,2574]$ & $\underset{(1,0767)}{3,1257^{* * * *}}[2,9029]$ & 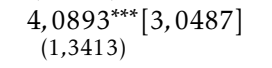 & $\underset{(1,0872)}{4,4787^{* * *}[4,1191]}$ \\
\hline$c i_{-2}$ & & & & $\underset{(3,0053)}{4,2270}[1,4065]$ & & $\underset{(2,8961)}{6,1639^{* * *}}[2,1283]$ \\
\hline$i c f_{-3}$ & & & & & $\underset{(2,4794)}{2,6927}[1,0859]$ & $\underset{(1,8161)}{3,6760^{*}} \quad[2,0240]$ \\
\hline Adjusted $R^{2}$ & 0,295 & 0,329 & 0,473 & 0,580 & 0,500 & 0,624 \\
\hline Adj. $R^{2}$ & 0,229 & 0,243 & 0,386 & 0,493 & 0,396 & 0,530 \\
\hline J-statistic & 6,361 & 6,527 & 5,891 & 6,280 & 5,630 & 5,319 \\
\hline Prob (J-statistic) & 0,848 & 0,769 & 0,751 & 0,616 & 0,689 & 0,621 \\
\hline Instrument rank & 15 & 15 & 15 & 15 & 15 & 15 \\
\hline
\end{tabular}

Nota: erros-padrão entre parênteses e estatísticas $t$ entre colchetes. Níveis de significância marginais: ${ }^{* * *}$ denota $1 \%$, ${ }^{* *}$ denota $5 \%$ e ${ }^{*}$ denota $10 \%$. 
maior previsibilidade a respeito do futuro dos preços e da atividade econômica. Assim, a credibilidade do regime de metas para inflação apresenta uma relação positiva com o iee.

$\mathrm{O}$ icf apresentou coeficientes positivos e significância estatística nas especificações principais (sp. 6). Por representar o comprometimento do governo com a sustentabilidade da dívida/PIB, uma redução na credibilidade fiscal pode indicar que as finanças públicas estão entrando em trajetória insustentável, o que resultaria em um ambiente macroeconômico mais instável e, portanto, menos favorável aos negócios.

De um modo geral, os resultados apontam que a credibilidade fiscal e a credibilidade monetária afetam as expectativas dos empresários industriais, pois, em parte, refletem as expectativas relacionadas ao ambiente macroeconômico futuro.

\subsection{Estimações para os determinantes do investimento}

De modo a analisar os determinantes macroeconômicos do investimento, dentre eles, a influência exercida pelas expectativas do empresário industrial, a seguinte equação foi estimada:

$$
\begin{aligned}
g f c f= & \theta_{1}+\theta_{2} \text { ice }_{-3}+\theta_{3} \text { iee }_{-1}+\theta_{4} \text { hiato }_{-1}+\theta_{5} \text { credito }_{-3}+ \\
& \theta_{6} \text { ir }_{\text {real }-1}+\theta_{7} \text { cambio }_{-2}+\theta_{8} \text { crise }+\mu
\end{aligned}
$$

em que, $\mu$ é o termo de erro. As derivadas parciais expressam as relações esperadas e, portanto, as hipóteses testadas:

$$
\frac{\varphi g f c f}{\varphi \text { ice }}>0 ; \frac{\varphi g f c f}{\varphi \text { iee }}>0 ; \frac{\varphi g f c f}{\text { phiato }}>0 ; \frac{\varphi g f c f}{\varphi c r e d i t o}>0 ; \frac{\varphi g f c f}{\varphi \text { ireal }_{\text {real }}}<0 ; \frac{\varphi g f c f}{\varphi c a m b i o}<0 ; \frac{\varphi g f c f}{\varphi c r i s e}<0 ;
$$

Com o objetivo de capturar o efeito dos choques financeiros internacionais originados pela crise do subprime e pela crise europeia sobre a economia brasileira, uma variável dummy (crise) foi incluída. A dummy assume valor 1 para os períodos compreendidos entre o terceiro trimestre de 2008 e o primeiro trimestre de 2009 e entre o segundo trimestre de 2010 e o primeiro trimestre de 2013 e assume valor zero para o restante do período da série. É esperado um coeficiente negativo para a variável dummy, pois com a desaceleração da economia mundial, a economia brasileira tende a caminhar no mesmo sentido, reduzindo assim o ritmo de investimentos.

As Tabelas 3 e 4 mostram as estimações para a equação (2). ${ }^{22}$

As estimações mostram que o efeito da confiança dos empresários em relação às condições atuais da economia (ice) sobre a formação bruta de capital fixo é positivo (especificações 2, 4 e 5 por MQO e GMM) e apresenta significância estatística (especificações 2, 4 e 5 por MQO e especificações 4 e 5 GMM). Embora, na especificação 1, o sinal encontrado seja negativo, este não apresenta significância estatística. Assim, as evidências apontam que uma percepção otimista dos empresários a respeito das condições atuais da economia e dos seus negócios estimula os investimentos, aumentando a formação bruta de capital fixo.

\footnotetext{
${ }^{22}$ As estimações por GMM utilizaram as seguintes variáveis instrumentais: $g f c f_{-1}, g f c f_{-2}$,

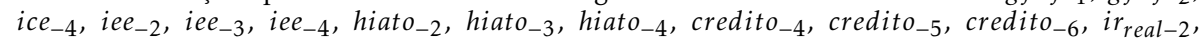
ir $_{\text {real }-3}$, cambio $_{-3}$.
} 
Tabela 3: Estimações MQO (gfcf)

\begin{tabular}{|c|c|c|c|c|c|}
\hline \multirow{2}{*}{$\begin{array}{l}\text { Variável dependente: gfcf } \\
\text { Variáveis Explicativas }\end{array}$} & \multicolumn{5}{|c|}{ MQO } \\
\hline & sp.1 & sp.2 & sp.3 & sp.4 & sp.5 \\
\hline constante & $\underset{(0.6559)}{10.9883^{* * *}}[16.7510]$ & 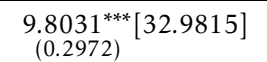 & $\underset{(0.2662)}{10.8419^{* * *}[40.7140]}$ & $\underset{(0.1823)}{11.0142^{* * *}[60.3921]}$ & $\underset{(0.2572)}{10.5187^{* * * *}[40.8819]}$ \\
\hline$i c e_{-3}$ & $-\underset{(0.0045)}{-0.0027} \quad[-0.5994]$ & $\underset{(0.0020)}{0.0043^{* * *}}[2.1564]$ & & $\underset{(0.0014)}{0.0035^{* *}}[2.3843]$ & $\underset{(0.0014)}{0.0043^{* * *}[3.1105]}$ \\
\hline$i e e_{-1}$ & $\underset{(0.0085)}{0.0052}[0.6139]$ & $\underset{(0.0036)}{0.0049}[1.3574]$ & $\underset{(0.0029)}{0,0048}[1.6505]$ & & $\underset{(0.0026)}{0.0067^{* *}}[2.544]$ \\
\hline hiato $_{-1}$ & $-\underset{(1.7873)}{0.2963}[-0.1658]$ & $\underset{(0.7915)}{2.1729^{* * *}}[2.7450]$ & $\underset{(0.6222)}{1.4005^{* *}}[2.2509]$ & $\underset{(0.4838)}{1.8423^{* * *}[3.8073]}$ & $\underset{(0.5694)}{0,9419}[1.6542]$ \\
\hline credito $_{-3}$ & & $\underset{(0.0025)}{0.0306^{* * *}}[12.168]$ & $\underset{(0.0035)}{0.0188^{* * * *}}[5.2901]$ & $\underset{(0.0033)}{0.0178^{* * * *}[5.2756]}$ & $\underset{(0.0031)}{0.0189^{* * * *}}[6.0201]$ \\
\hline$i r_{\text {real-1 }}$ & & & $\underset{(0.0058)}{-0,0064} \quad[-1.0998]$ & $-\underset{(0.0055)}{0.0141^{* *}}[-2.5485]$ & $-\underset{(0.0053)}{-0.0101^{*}} \quad[-1.9013]$ \\
\hline cambio $_{-2}$ & & & $\begin{array}{l}-0.1749^{* * *}[-5.2845] \\
(0.0331)\end{array}$ & $\underset{(0.0309)}{-0.1466^{* * *}[-4.7430]}$ & $\underset{(0.0294)}{-0.1653^{* * *}[-5.6170]}$ \\
\hline crise & $\underset{(0.0603)}{0.3733^{* * *}[6.1857]}$ & $-\underset{(0.0482)}{-0.1224^{* *}}[-2.5385]$ & $\underset{(0.0365)}{-0.0672^{*}} \quad[-1.8386]$ & $\underset{(0.0368)}{-0.0973^{* *}}[-2.6450]$ & $-\underset{(0.0339)}{-0.0997^{* * *}[-2.9375]}$ \\
\hline Adjusted $R^{2}$ & 0,539 & 0,915 & 0,951 & 0,955 & 0,961 \\
\hline F-statistic (p-valor) & 0,000 & 0,000 & 0,000 & 0,000 & 0,000 \\
\hline Ramsey - RESET (1)(p-value) & 0,483 & 0,003 & 0,016 & 0,918 & 0,227 \\
\hline Jarque-Bera ( $\mathrm{p}$-value) & 0,738 & 0,273 & 0,398 & 0,431 & 0,040 \\
\hline $\operatorname{ARCH}(1)(p-v a l u e)$ & 0,000 & 0,938 & 0,294 & 0,400 & 0,561 \\
\hline $\mathrm{ARCH}(2)(\mathrm{p}$-value $)$ & 0,002 & 0,725 & 0,000 & 0,002 & 0,028 \\
\hline ARCH (4)(p-value) & 0,015 & 0,957 & 0,001 & 0,005 & 0,139 \\
\hline ARCH (8)(p-value) & 0,104 & 0,997 & 0,027 & 0,035 & 0,468 \\
\hline $\mathrm{LM}(1)(\mathrm{p}$-value $)$ & 0,000 & 0,001 & 0,637 & 0,837 & 0,899 \\
\hline $\mathrm{LM}(2)(\mathrm{p}$-value $)$ & 0,000 & 0,005 & 0,000 & 0,000 & 0,000 \\
\hline LM(3)(p-value) & 0,000 & 0,004 & 0,000 & 0,000 & 0,000 \\
\hline LM(4)(p-value) & 0,000 & 0,002 & 0,000 & 0,000 & 0,000 \\
\hline
\end{tabular}

Nota: erros-padrão entre parênteses e estatísticas $t$ entre colchetes. Níveis de significância marginais: ${ }^{* * *}$ denota $1 \%,{ }^{* * *}$ denota $5 \%$ e denota $10 \%$. 
Tabela 4: Estimações GMM (gfcf)

\begin{tabular}{|c|c|c|c|c|c|c|}
\hline \multirow{2}{*}{$\frac{\text { Variável dependente: iee }}{\text { Variáveis Explicativas }}$} & \multicolumn{6}{|c|}{ GMM } \\
\hline & \multicolumn{2}{|c|}{ sp.1 } & sp.2 & sp. 3 & sp. 4 & sp. 5 \\
\hline constante & $\begin{array}{r}11,7778 \\
(0,5370)\end{array}$ & {$[21,9313]$} & $\underset{(0,2384)}{10,6313^{* * * *}}[44,5797]$ & $\underset{(0,2043)}{10,9234^{* * * *}}[53,4633]$ & $\underset{(0,1823)}{10,8231^{* * *}[59,3385]}$ & $\begin{array}{c}10,4514^{* * *}[59,5436] \\
(0,1755)\end{array}$ \\
\hline$i^{i c e} e_{-3}$ & $\begin{array}{r}-0,0082 \\
(0,0027)\end{array}$ & {$[-3,0067]$} & $\underset{(0,0016)}{0,0011}[0,6568]$ & & $\underset{(0,0011)}{0,0034^{* * * *}}[3,0866]$ & $\underset{(0,0008)}{0,0050^{* * *}[6,2754]}$ \\
\hline$i e e_{-1}$ & $\begin{array}{r}-0,0031 \\
(0,0065)\end{array}$ & {$[-0,4772]$} & $\begin{array}{r}-0,0052^{*} \\
(0,0028)\end{array}$ & $\underset{(0,0022)}{0,0013}[0,5792]$ & & $\begin{array}{l}0,0073^{* * * *}[3,4849] \\
(0,0021)\end{array}$ \\
\hline hiato $_{-1}$ & $\begin{array}{l}1,2155 \\
(1,5085)\end{array}$ & {$[0,8057]$} & $\underset{(0,9384)}{4,4761^{* * * *}}[4,7699]$ & $\underset{(0,7222)}{2,4353^{* * *}}[3,3719]$ & $\underset{(0,5240)}{2,4501^{* * *}}[4,6750]$ & $\underset{(0,5584)}{0,9570^{*}} \quad[1,7137]$ \\
\hline credito $_{-3}$ & & & $\underset{(0,0026)}{0,0306^{* * * *}[11,692]}$ & $\underset{(0,0043)}{0,0209^{* * *}[4,8347]}$ & $\begin{array}{l}0,0219^{* * * *}[6,2757] \\
(0,0035)\end{array}$ & $\begin{array}{l}0,0204^{* * *}[6,6405] \\
(0,0030)\end{array}$ \\
\hline$i r_{\text {real }-1}$ & & & & $\underset{(0,0045)}{-0,0046} \quad[-1,0120]$ & $\underset{(0,0037)}{-0,0086^{* *}}[-2,3044]$ & $\underset{(0,0034)}{-0,0084^{* *}}[-2,4813]$ \\
\hline cambio $_{-2}$ & & & & $\begin{array}{l}-0,1440^{* * * *}[-6,0935] \\
(0,0236)\end{array}$ & $\begin{array}{l}-0,1337^{* * *}[-7,7676] \\
\quad(0,0172)\end{array}$ & $\begin{array}{l}-0,1906^{* * *}[-8,0384] \\
(0,0237)\end{array}$ \\
\hline crise $_{\text {subprime }}$ euro & $\begin{array}{l}0,4288 \\
(0,0490)\end{array}$ & {$[8,7453]$} & $\begin{array}{l}-0,1502^{* * *}[-2,9501] \\
\underset{(0,0509)}{ }\end{array}$ & $\begin{array}{r}-0,0909^{*} \\
(0,0467)\end{array} \quad[-1,9482]$ & $\begin{array}{l}-0,1367^{* * *}[-3,4534] \\
\quad(0,0396)\end{array}$ & $\begin{array}{l}-0,1370^{* * *}[-3,6027] \\
\quad(0,0380)\end{array}$ \\
\hline Adjusted $R^{2}$ & 0,5 & 59 & 0,903 & 0,947 & 0,951 & 0,958 \\
\hline Adj. $R^{2}$ & 0,5 & 01 & 0,886 & 0,936 & 0,941 & 0,947 \\
\hline J-statistic & 6,6 & 64 & 7,537 & 7,822 & 7,769 & 7,856 \\
\hline Prob (J-statistic) & 0,8 & 26 & 0,674 & 0,552 & 0,558 & 0,448 \\
\hline Instrument rank & 1 & 6 & 16 & 16 & 16 & 16 \\
\hline
\end{tabular}

Nota: erros-padrão entre parênteses e estatísticas $t$ entre colchetes. Níveis de significância marginais: ${ }^{* * *}$ denota $1 \%,{ }^{* *}$ denota $5 \%$ e ${ }^{*}$ denota $10 \%$. 
O efeito das expectativas dos empresários (iee) é positivo na maioria das especificações (especificações 1, 2, 3 e 5 por MQO e especificações 3 e 5 por GMM) e possui significância estatística na principal especificação (especificação 5). Assim, os resultados apontam que não apenas as condições atuais da economia na visão dos empresários são importantes para a formação bruta de capital fixo, mas, também, suas expectativas a respeito da economia e de seus negócios no futuro. Portanto, as evidências apontam que expectativas mais otimistas a respeito da economia no futuro exercerão impacto positivo sobre o aumento da capacidade produtiva.

Em relação ao hiato do produto, nas estimações por MQO, as especificações 2, 3, 4 e 5 apresentaram coeficientes positivos e estatisticamente significativos e, na especificação 1 o coeficiente apresentou sinal negativo, contudo sem significância estatística. Por GMM, todos os coeficientes estimados para o hiato do produto foram positivos e a significância estatística foi encontrada nas especificações $(2,3,4$ e 5). Assim, quanto mais aquecida estiver a economia e, portanto, maior o hiato do produto com sinal positivo, as decisões de investimento serão estimuladas.

As estimativas para o credito apresentaram coeficientes positivos e significância estatística em todas as especificações por MQO e GMM. Uma maior oferta de crédito funciona como estímulo à atividade econômica, aos investimentos e, consequentemente, à formação bruta de capital fixo.

Os resultados apontam que o efeito da $i r_{\text {real }}$ é negativo (em todas as especificações testadas por MQO e GMM, ou seja, especificações 3, 4 e 5) e possui significância estatística (especificações 4 e 5 por MQO e GMM). Nesse sentido, os resultados sugerem que uma taxa de juros real mais elevada aumenta o custo do capital, tornando os investimentos mais caros para os empresários. Dessa forma, quando a taxa de juros real aumenta, o estímulo ao aumento da capacidade produtiva se reduz, reduzindo a formação bruta de capital fixo.

Os coeficientes estimados para o cambio foram negativos e estatisticamente significativos em todas as especificações testadas, quer seja por MQO ou GMM. Assim, uma taxa de câmbio mais alta eleva o custo de importação de bens de capital, reduzindo assim a formação bruta de capital fixo. Esse resultado também foi encontrado por de Mendonça \& Lima (2011).

Como teste de robustez, e pelo fato da análise utilizar as expectativas do setor industrial para explicar os investimentos e, portanto, a formação de capital na economia, a equação (2) foi reestimada utilizando a produção industrial ${ }^{23}$ para o cálculo do hiato do produto. ${ }^{24}$ Os resultados (apresentados na Tabela A.2 do Apêndice) corroboram aqueles encontrados e apresentados nas Tabelas 3 e 4 .

\footnotetext{
${ }^{23}$ A série utilizada para o cálculo do hiato do produto industrial foi obtida do Banco Central do Brasil - série no 1237 - PIB trimestral (1995=100) - Dados dessazonalizados - Indústria (total). A série original foi gerada pelo IBGE. Foi aplicado o logaritmo natural na série e, posteriormente, sua tendência de longo prazo foi obtida por meio do filtro Hodrick-Prescott. O hiato é calculado pela diferença entre o logaritmo natural do PIB industrial e sua tendência de longo prazo.

${ }^{24}$ As estimações por GMM utilizaram as seguintes variáveis instrumentais: $g f c f_{-1}, g f c f_{-2}$,

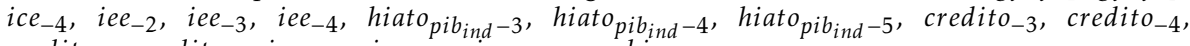
credito -5, credito $_{-6}, i r_{\text {real }-1}, i r_{\text {real }-2}, i r_{\text {real }-3}$, cambio $_{-3}$.
} 


\subsection{Estimações para os determinantes do emprego}

De modo a analisar os determinantes macroeconômicos do emprego, dentre eles, a influência exercida pelas expectativas do empresário industrial, a seguinte equação foi estimada:

$$
\begin{aligned}
\text { emp }= & \alpha_{1}+\alpha_{2} \text { ice }_{-4}+\alpha_{3} \text { iee }_{-1}+\alpha_{4} \text { hiato }_{-3}+\alpha_{5} \text { credito }_{-1}+ \\
& \alpha_{6} \text { ir }_{\text {real }-1}+\alpha_{7} \text { cambio }_{-2}+\alpha_{8} d_{\text {sal }_{\text {real }}-2}+\eta
\end{aligned}
$$

em que, $\eta$ é o termo de erro. As derivadas parciais expressam as relações esperadas e, portanto, as hipóteses testadas:

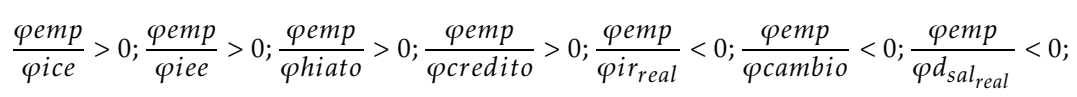

As Tabelas 5 e 6 apresentam as estimações para a equação (3). ${ }^{25}$

As estimações mostram que o efeito da confiança dos empresários em relação às condições atuais da economia (ice) sobre o emprego é positivo. Portanto, uma percepção otimista dos empresários a respeito das condições atuais da economia e dos seus negócios estimula a oferta de empregos no setor industrial. Ademais, o efeito das expectativas dos empresários (iee) é positivo e apresenta significância estatística. Isso significa que não apenas as condições atuais da economia na visão dos empresários são importantes para o emprego, como também suas expectativas a respeito da economia e de seus negócios no futuro. Assim, expectativas mais otimistas a respeito da economia no futuro exercerão impacto positivo também sobre o emprego no setor industrial.

O hiato do produto apresentou coeficientes positivos e significância estatística. Quanto mais a economia estiver aquecida, maior será o estímulo ao aumento da produção e, consequentemente, maior será a demanda por trabalhadores. Além disso, as estimativas para o credito apresentaram coeficientes positivos e significância estatística. Uma maior oferta de crédito funciona como estímulo à atividade econômica, à produção e, consequentemente, ao emprego.

O efeito estimado para a $i r_{\text {real }}$ foi negativo e apresentou significância estatística. Dessa forma, quando a taxa de juros real aumenta, o estímulo ao aumento da capacidade produtiva se reduz, reduzindo a oferta de emprego. Por sua vez, os resultados sugerem que variações positivas do salário real desestimulam o emprego, pois o custo da mão de obra encarece, contudo, esse resultado não é tão forte (embora todos os coeficientes apresentem sinais negativos, a significância estatística somente foi encontrada na especificação 4 estimada por GMM).

O efeito do cambio é negativo e apresentou significância estatística. Uma taxa de câmbio mais alta eleva o custo de importação de bens de capital, reduzindo assim o estímulo ao aumento da produção e, consequentemente, reduzindo a necessidade de mais trabalhadores.

\subsection{Sistema de equações para expectativas do empresário industrial e investimento}

As evidências até então apresentadas apontam que a maior credibilidade do regime de metas para inflação e a maior credibilidade fiscal contribuem para

\footnotetext{
${ }^{25}$ As estimações por GMM utilizaram as seguintes variáveis instrumentais: $e m p_{-1}, i c e_{-5}, i c e_{-6}$, iee $_{-2}$, iee $_{-3}$, hiato $_{-4}$, credito $_{-2}, i r_{\text {real }-2}, i r_{\text {real }-3}$, cambio $_{-3}$, cambio $_{-4}, d_{\text {sal }_{\text {real }}-3}, d_{\text {sal }_{\text {real }}-4}$.
} 
Tabela 5: Estimações MQO (emp)

\begin{tabular}{|c|c|c|c|c|}
\hline \multirow{2}{*}{$\begin{array}{l}\text { Variável dependente: emp } \\
\text { Variáveis Explicativas }\end{array}$} & \multicolumn{4}{|c|}{ MQO } \\
\hline & sp.1 & sp.2 & sp.3 & sp.4 \\
\hline constante & $\underset{(6.9211)}{54.6932^{* * *}}[7.9022]$ & $\begin{array}{l}97.6412^{* * *}[10.7585] \\
(9.0756)\end{array}$ & $\underset{(4.9409)}{114.9238^{* * *}}[23.2592]$ & $\underset{(8.8181)}{91.1389^{* * *}}[10.33534]$ \\
\hline$i^{i c e} e_{-4}$ & $\underset{(0.0432)}{0.1123^{* *}}[2.5986]$ & & $\underset{(0.0435)}{0.0394}[0.9045]$ & $\underset{(0.0305)}{0.0727^{* *}}[2.3778]$ \\
\hline$i_{e} e_{-1}$ & $\underset{(0.0898)}{0.3168^{* * * *}[3.5247]}$ & $\underset{(0.0838)}{0.2051^{* *}}[2.4480]$ & & $\underset{(0.0790)}{0.2302^{* * *}[2.9121]}$ \\
\hline hiato $_{-3}$ & $\underset{(21.6411)}{12.3291}[0.5697]$ & $\underset{(13.5373)}{37.1189^{* * *}}[2.7419]$ & $\underset{(15.8615)}{36.4627^{* *}}[2.2988]$ & $\underset{(13.8227)}{26.5538^{*}}[1.9210]$ \\
\hline credito $_{-1}$ & $\underset{(0.0553)}{0.7136^{* * *}}[12.8936]$ & $\underset{(0.0738)}{0.3315^{* * * *}[4.4890]}$ & $\underset{(0.0799)}{0.2109^{* * *}}[2.6383]$ & $\begin{array}{c}0.3375^{* * * *}[4.5708] \\
(0.0738)\end{array}$ \\
\hline$i r_{\text {real-1 }}$ & & $\underset{(0.1682)}{-0.3201^{*}} \quad[-1.9030]$ & $\frac{-0.6006^{* * * *}}{(0.2046)}[-2.9347]$ & $\underset{(0.1553)}{-0.3377^{* *}}[-2.1750]$ \\
\hline cambio $_{-2}$ & & $\underset{(1.0070)}{-6.6968^{* * *}[-6.6499]}$ & $\underset{(1.0398)}{-6.5904^{* * * *}}[-6.3378]$ & $\begin{array}{l}-6.1008^{* * *}[-6.1572] \\
(0.9908)\end{array}$ \\
\hline$d_{\text {sal }}$ real-2 & $\underset{(0.0555)}{-0.0489} \quad[-0.8809]$ & $\underset{(0.0411)}{-0.0364} \quad[-0.8855]$ & $\begin{array}{rr}-0,0258 & {[-0.6504]} \\
(0.0397) & \\
\end{array}$ & $\begin{array}{c}-0.0378 \\
(0.0397)\end{array} \quad[-0.9504]$ \\
\hline Adjusted $R^{2}$ & 0,908 & 0,968 & 0,952 & 0,969 \\
\hline F-statistic (p-valor) & 0,000 & 0,000 & 0,000 & 0,000 \\
\hline Ramsey - RESET (1)(p-value) & 0,047 & 0,347 & 0,096 & 0,949 \\
\hline Jarque-Bera (p-value) & 0,667 & 0,275 & 0,002 & 0,087 \\
\hline ARCH (1)(p-value) & 0,000 & 0,229 & 0,073 & 0,096 \\
\hline $\operatorname{ARCH}(2)(p-v a l u e)$ & 0,020 & 0,684 & 0,225 & 0,902 \\
\hline $\mathrm{ARCH}(4)(\mathrm{p}$-value $)$ & 0,000 & 0,999 & 0,483 & 0,896 \\
\hline $\operatorname{ARCH}(8)(\mathrm{p}$-value $)$ & 0,004 & 0,994 & 0,875 & 0,824 \\
\hline $\mathrm{LM}(1)(\mathrm{p}$-value $)$ & 0,000 & 0,000 & 0,000 & 0,002 \\
\hline $\operatorname{LM}(2)(\mathrm{p}$-value $)$ & 0,000 & 0,000 & 0,000 & 0,008 \\
\hline $\operatorname{LM}(3)(\mathrm{p}$-value $)$ & 0,000 & 0,001 & 0,001 & 0,012 \\
\hline LM(4)(p-value) & 0,000 & 0,002 & 0,002 & 0,026 \\
\hline
\end{tabular}

Nota: erros-padrão entre parênteses e estatísticas $t$ entre colchetes. Níveis de significância marginais: ${ }^{* * *}$ denota $1 \%$, ** denota $5 \% \mathrm{e}^{*}$ denota $10 \%$. 
Tabela 6: Estimações GMM (emp)

\begin{tabular}{|c|c|c|c|c|}
\hline \multirow{2}{*}{$\begin{array}{l}\text { Variável dependente: iee } \\
\text { Variáveis Explicativas }\end{array}$} & \multicolumn{4}{|c|}{ GMM } \\
\hline & sp.1 & sp.2 & sp.3 & sp.4 \\
\hline constante & $\underset{(7,3931)}{52,3371^{* * *}}[7,0790]$ & $\begin{array}{c}92,5374^{* * *} \\
(6,9125)\end{array}$ & $\begin{array}{c}111,4869^{* * *} \\
(1,9946)\end{array}$ & $\begin{array}{c}92,6964^{* * *} \\
(5,6857)\end{array}$ \\
\hline$i_{c e}-4$ & $\underset{(0,0592)}{0,0976} \quad[1,6482]$ & & $\begin{array}{l}0,0965^{* * * *} \\
\underset{(0,0299)}{ }[3,2191]\end{array}$ & $\underset{(0,0273)}{0,1169^{* * *}}[4,2729]$ \\
\hline$i e e_{-1}$ & $\begin{array}{l}0,3994^{* * *}[5,1743] \\
(0,0772)\end{array}$ & $\begin{array}{l}0,2380^{* * *}[3,8071] \\
(0,0625)\end{array}$ & & $\begin{array}{l}0,2233^{* * * *}[3,7728] \\
(0,0591)\end{array}$ \\
\hline hiato $_{-3}$ & $\underset{(20,2611)}{31,8203}[1,5705]$ & $\begin{array}{l}49,6189^{* * * *}[4,5119] \\
\underset{(10,9971)}{ }\end{array}$ & $\underset{(12,6446)}{34,4522^{* *}}[2,7246]$ & $\underset{(13,0881)}{3,03542^{*}}[1,7600]$ \\
\hline credito $_{-1}$ & $\underset{(0,0198)}{0,6585^{* * *}[33,1243]}$ & $\begin{array}{l}0,3528^{* * *}[5,7645] \\
(0,0612)\end{array}$ & $\underset{(0,0357)}{0,1980^{* * *}[5,5360]}$ & $\underset{(0,0541)}{0,2604^{* * * *}[4,8122]}$ \\
\hline$i r_{\text {real-1 }}$ & & $\underset{(0,1008)}{-0,2301^{* * *}}[-2,2829]$ & $\begin{array}{l}-0,7119^{* * *}[-8,3289] \\
(0,0854)\end{array}$ & $\begin{array}{c}-0,4838^{* * *} \\
(0,1252)\end{array}$ \\
\hline cambio $_{-2}$ & & 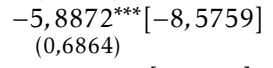 & $\begin{array}{l}-5,5315^{* * * *}[-10,2514] \\
\quad(0,5395)\end{array}$ & $\begin{array}{l}-5,6864^{* * *}[-10,633] \\
(0,5347)\end{array}$ \\
\hline$d_{\text {sal }} l_{\text {real }}$ & $\underset{(0,0931)}{0,0519} \quad[0,5577]$ & $\begin{array}{c}0,0154 \\
(0,0533)\end{array} \quad[0,2892]$ & $\begin{array}{c}-0,0680 \\
(0,0419)\end{array} \quad[-1,6200]$ & $\begin{array}{r}-0,0767^{*} \quad[-1,8042] \\
(0,0425)\end{array}$ \\
\hline Adjusted $R^{2}$ & 0,927 & 0,976 & 0,954 & 0,978 \\
\hline Adj. $R^{2}$ & 0,915 & 0,971 & 0,944 & 0,972 \\
\hline J-statistic & 6,320 & 7,942 & 5,011 & 4,473 \\
\hline Prob (J-statistic) & 0,611 & 0,338 & 0,659 & 0,613 \\
\hline Instrument rank & 14 & 14 & 14 & 14 \\
\hline
\end{tabular}

Nota: erros-padrão entre parênteses e estatísticas $t$ entre colchetes. Níveis de significância marginais: ${ }^{* * *}$ denota $1 \%$, ** denota $5 \% \mathrm{e}^{*}$ denota $10 \%$. 
a formação de expectativas mais otimistas com relação ao futuro da economia por parte dos empresários. Por sua vez, as evidências apontam que alterações nas expectativas dos empresários afetam a formação bruta de capital fixo e o emprego. Uma maneira de observar o mecanismo de transmissão é por meio da estimação de sistemas de equações. Assim, para dar robustez aos resultados anteriormente obtidos nas estimativas individuais, o seguinte sistema de equações foi estimado por GMM: ${ }^{26}$

$$
\text { Sistema }\left\{\begin{aligned}
\text { iee }= & y_{1}+y_{2} \text { ice }_{-1}+y_{3} d_{\text {ex }} \text { pinf } f_{-3}+y_{4} y_{e-1}+y_{5} \text { selic }_{e-1}+ \\
& y_{6} \text { cambio }_{e-2}+y_{7} \text { ci }_{-2}+y_{8} i c f_{-3}+\sigma \\
g f c f= & \rho_{1}+\rho_{2} i c e_{-3}+\rho_{3} i e e_{-1}+\rho_{4} \text { hiato }_{-1}+\rho_{5} \text { credito }_{-3}+ \\
& \rho_{6} \text { ir }_{\text {real }-1}+\rho_{7} \text { cambio }_{-2}+\rho_{8} \text { crise }+\vartheta
\end{aligned}\right.
$$

em que, $\sigma$ e $\vartheta$ são termos de erro aleatórios. A Tabela 7 mostra a estimação do sistema.

Todos os coeficientes apresentaram sinais de acordo com a teoria e com significância estatística. O sistema revela, assim como nas estimações individuais, a importância das credibilidades (monetária e fiscal) para o comportamento da iee. Ou seja, quando o ambiente macroeconômico fica mais estável, os agentes conseguem fazer melhor previsão a respeito do futuro da economia. Além disso, os coeficientes estimados pelo sistema de equações apresentaram maior significância estatística, ou seja, a estimação por meio do sistema aumentou consideravelmente a acurácia dos coeficientes no modelo (os errospadrão são menores e as estatísticas $t$ são maiores).

Tabela 7: Sistema GMM (iee e gfcf)

\begin{tabular}{|c|c|c|c|}
\hline \multicolumn{4}{|c|}{ GMM sistêmico — iee e gfcf } \\
\hline Variáveis Dependentes & iee & & gfcf \\
\hline Variáveis Explicativas & \multicolumn{3}{|c|}{ Variáveis Explicativas } \\
\hline constante & $\begin{array}{c}25,0708^{* * * *}[7,2044] \\
(3,4799)\end{array}$ & constante & $\underset{(0,1327)}{10,377^{* * * *}[78,1648]}$ \\
\hline ice $_{-1}$ & $\underset{(0,0440)}{0,2281^{* * * *}}[5,1836]$ & $i c e_{-3}$ & $\underset{(0,0005)}{0,0053^{* * *}}[9,2269]$ \\
\hline$d_{\text {expinf }-3}$ & $\begin{array}{l}-4,0395^{* * *}[-4,7070] \\
\underset{(0,8581)}{ }\end{array}$ & $i e e_{-1}$ & $\begin{array}{l}0,0079^{* * *}[4,8917] \\
\underset{(0,0016)}{ }\end{array}$ \\
\hline$y_{e-1}$ & $\begin{array}{c}3,8960 * *^{* * *}[6,4896] \\
(0,6003)\end{array}$ & hiato $_{-1}$ & $\underset{(0,4668)}{0,8518^{*}} \quad[1,8248]$ \\
\hline selic $_{e-1}$ & $\begin{array}{l}-0,6184^{* * * *}[-6,4187] \\
\quad(0,0963)\end{array}$ & credito -3$)$ & $\begin{array}{l}0,0207^{* * *} \\
\underset{(0,0023)}{(8,9596]}\end{array}$ \\
\hline cambio $_{e-2}$ & $\underset{(0,7629)}{4,1949^{* * * *}}[5,4982]$ & $i r_{\text {real-1 }}$ & $\underset{(0,0024)}{-0,0084^{* * * *}[-3,5211]}$ \\
\hline$c i_{-2}$ & $\underset{(2,1940)}{5,4782^{* *}}[2,4969]$ & cambio $_{-2}$ & $\begin{array}{l}-0,1844^{* * *}[-11,1870] \\
\quad(0,0164)\end{array}$ \\
\hline$i c f_{-3}$ & $\begin{array}{l}3,9438^{* * *}[2,7355] \\
(1,4417)\end{array}$ & crise & $\begin{array}{c}-0,1400^{* * * *}[-4,9188] \\
(0,0284)\end{array}$ \\
\hline $\mathrm{R}^{2}$ & 0,596 & & 0,958 \\
\hline $\mathrm{R}^{2}$ ajustado & 0,495 & & 0,947 \\
\hline Estatistica J & & & \\
\hline Prob.(est. J) & & & \\
\hline
\end{tabular}

Níveis de significância marginais: ${ }^{* * *}$ denota $0,01,{ }^{* *}$ denota $0,05 \mathrm{e}^{*}$ denota 0,1 . Erro padrão entre parênteses e estatística t entre colchetes.

\footnotetext{
${ }^{26} \mathrm{O}$ Sistema GMM utiliza as mesmas variáveis instrumentais das estimações individuais.
} 


\subsection{Sistema de equações para expectativas do empresário industrial e emprego}

Para verificar a robustez dos resultados obtidos nas estimativas individuais em relação aos determinantes das expectativas do empresário industrial e do emprego, o seguinte sistema de equações foi estimado por GMM: ${ }^{27}$

$$
\text { Sistema }\left\{\begin{aligned}
& \text { iee }= \phi_{1}+\phi_{2} i c e_{-1}+\phi_{3} d_{\text {exp }} i n f_{-3}+\phi_{4} y_{e-1}+\phi_{5} \text { selic }_{e-1}+ \\
& \phi_{6} \text { cambio }_{e-2}+\phi_{7} \text { ci }_{-2}+\phi_{8} i c f_{-3}+v \\
& \text { emp }= \delta_{1}+\delta_{2} i c e_{-4}+\delta_{3} i e e_{-1}+\delta_{4} \text { hiato }_{-3}+\delta_{5} \text { credito }_{-1}+ \\
& \delta_{6} \text { ir }_{\text {real }-1}+\delta_{7} \text { cambio }_{-2}+\delta_{8} d_{\text {sal }} \text { real } \\
&
\end{aligned}\right.
$$

em que, $v$ e $\tau$ são termos de erro aleatórios. A Tabela 8 mostra a estimação do sistema.

Tabela 8: Sistema GMM (iee e emp)

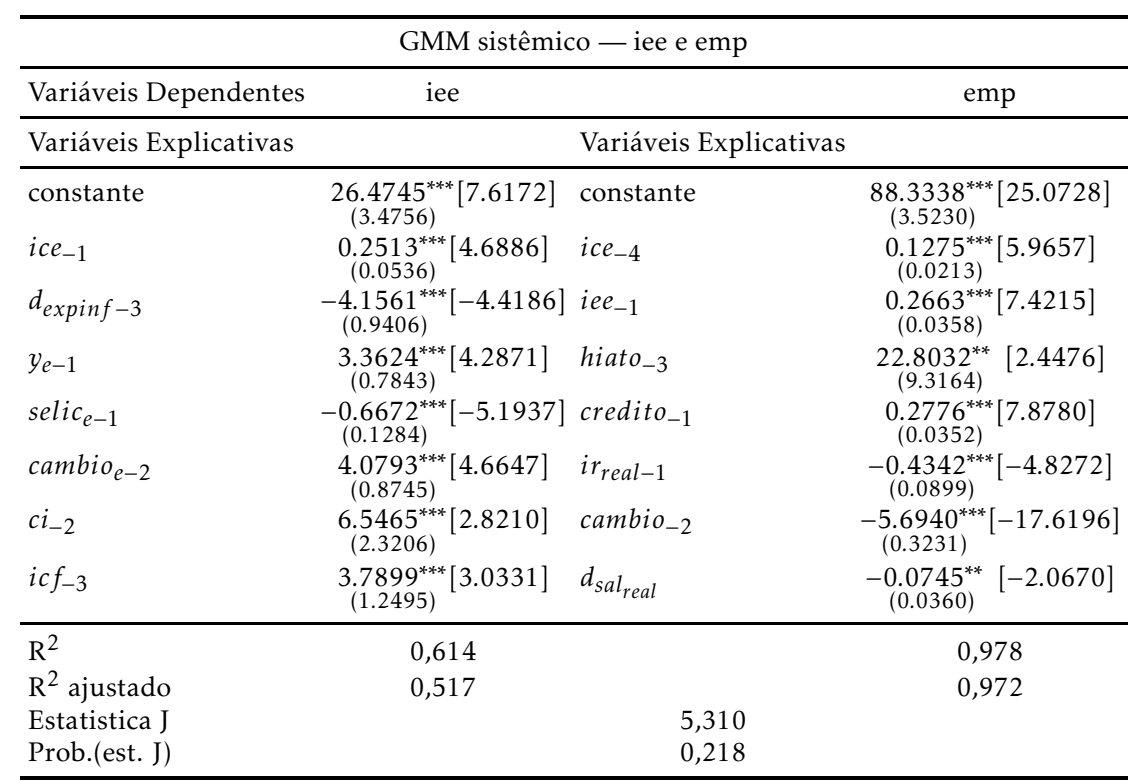

Níveis de significância marginais: ${ }^{* * *}$ denota $0,01,{ }^{* *}$ denota $0,05 \mathrm{e}^{*}$ denota 0,1 . Erro padrão entre parênteses e estatística t entre colchetes.

Todos os coeficientes apresentaram sinais de acordo com o esperado e com significância estatística. O sistema revela a importância de um ambiente macroeconômico estável, em que governo e autoridade monetária estão comprometidos com seus objetivos, para o processo de formação de expectativas dos empresários industriais e, por sua vez, a influência dessas expectativas sobre o emprego.

\section{Conclusão}

O presente trabalho buscou apresentar evidências empíricas acerca da importância das credibilidades tanto do regime de metas para inflação como da

\footnotetext{
${ }^{27}$ O Sistema GMM utiliza as mesmas variáveis instrumentais das estimações individuais.
} 
condução da política fiscal para a formação das expectativas dos empresários industriais no Brasil. Os resultados sugerem que o comprometimento das autoridades monetária e fiscal com seus objetivos exerce papel fundamental na formação das expectativas dos empresários com relação ao que esperam para o futuro da economia, o que, por sua vez, irá exercer influência sobre o processo de tomada de decisões relativas ao investimento e ao emprego.

Em particular, o trabalho analisou a influência das expectativas formadas em relação às variáveis macroeconômicas sobre as expectativas formadas pelos empresários industriais em relação ao futuro da economia. As evidências encontradas apontam que as expectativas dos empresários industriais são sensíveis às expectativas formadas para variáveis macroeconômicas importantes (tais como, inflação, crescimento do produto, taxa básica de juros e taxa de câmbio). Ademais, os achados apontam que o investimento agregado e o emprego são afetados pelos canais de transmissão da taxa de juros, do crédito, da taxa de câmbio e das expectativas.

\section{Referências Bibliográficas}

Agénor, P. \& Taylor, M. P. (1992), 'Testing for credibility effects', IMF Staff Papers 39, 545-571.

Agénor, P. \& Taylor, M. P. (1993), 'Analysing credibility in high-inflation countries: a new approach', Economic Journal 103, 329-336.

Cati, R. C., Garcia, M. G. P. \& Perron, P. (1999), 'Unit roots in the presence of abrupt governmental interventions with an application to brazilian data', Journal of Applied Econometrics 14, 27-56.

Cecchetti, S. G. \& Krause, S. S. (2002), 'Central bank structure, policy efficiency and macroeconomic performance: Exploring empirical relationships', Federal Reserve Bank of St. Louis Review 84(4), 45-60.

Christiano, L. J. \& Fitzgerald, T. J. (2000), 'Understanding the fiscal theory of the price level', Federal Reserve Bank of Cleveland Economic Review 36(2), 137.

Cragg, J. G. (1983), 'More efficient estimation in the presence of heteroscedasticity of unknown form', Econometrica 51(3), 751-763.

Cukierman, A. (1992), Central Bank Strategy, Credibility, and Independence: Theory and Evidence.

Cukierman, A. \& Meltzer, A. H. (1986), 'A theory of ambiguity, credibility and inflation under discretion and asymmetric information', Econometrica 54(1099-1128).

de Mendonça, H. F. (2004), 'Dívida pública e estabilidade de preços no período pós-real: explorando relações empíricas', Estudos Econômicos 34(2), 345-368.

de Mendonça, H. F. (2007), 'Towards credibility from inflation targeting: the brazilian experience', Applied Economics 39, 2599-2615. 
de Mendonça, H. F. \& da Silva, R. T. (2008), 'Administração da dívida pública sob um regime de metas para inflação: evidências para o caso brasileiro', Economia Aplicada 12(4), 635-657.

de Mendonça, H. F. \& Lima, T. R. V. S. (2011), 'Macroeconomic determinants of investment under inflation targeting: Empirical evidence from the brazilian economy', Latin American Business Review 12(1), 25-38.

de Mendonça, H. F. \& Machado, M. R. (2013), 'Public debt management and credibility: Evidence from an emerging economy', Economic Modelling 30, 10-21.

de Mendonça, H. F. \& Souza, G. J. G. (2009), 'Inflation targeting credibility and reputation: The consequences for the interest rate', Economic Modelling 26(1228-1238).

Franses, P. H. \& Haldrup, N. (1994), 'The effects of additive outliers on tests for unit roots and cointegration', Journal of Business and Economic Statistics $12,471-478$.

Grenne, J. \& Villanueva, D. (1991), 'Private investment in developing countries: an empirical analysis', IMF Staff Papers 38(1).

Hansen, L. P. (1982), 'Large sample properties of generalized method of moments estimators', Econometrica 50(4), 1029-1054.

IMF (2002), Assessing sustainability, Prepared by the policy development and review department. in consultation with the fiscal affairs, international capital markets, monetary and exchange affairs, and research departments, International Monetary Fund, Washington D.C. p. 25.

Kwiatkowski, D., Phillips, P., Schmidt, P. \& Shin, Y. (1992), 'Testing the null hypothesis of stationarity against the alternative of a unit root', Journal of Econometrics 54, 159-178.

Kydland, F. E. \& Prescott, E. C. (1977), 'Rules rather than discretion: the inconsistency of optimal plans', Journal of Political Economy 85(3), 473-492.

Luporini, V. \& Alves, J. (2010), 'Investimento privado: uma análise empírica para o brasil', Economia e Sociedade 19(3), 449-475.

Melo, G. M. \& Rodrigues Jr, W. (1998), Determinantes do investimento privado no brasil: 1970-1995, Texto para Discussão 605, IPEA, Brasilia.

Montes, G. C. (2013), 'Credibility and monetary transmission channels under inflation targeting: an econometric analysis from a developing country', Economic Modelling 30, 670-684.

Montes, G. C. \& Bastos, J. C. A. (2011), 'Metas de inflação e estrutura a termo das taxas de juros no brasil', Economia Aplicada 15(3), 391-415.

Montes, G. C. \& Bastos, J. C. A. (2013), 'Economic policies, macroeconomic environment and entrepreneurs' expectations: Evidence from brazil', Journal of Economic Studies 40(3), 334-354. 
Montes, G. C. \& Bastos, J. C. A. (2014), 'Effects of reputation and credibility on monetary policy: Theory and evidence for brazil', Journal of Economic Studies 41(3).

Moreira, A. \& Rocha, K. (2011), 'A política fiscal e as taxas de juros nos países emergentes', Economia Aplicada 15(3), 485-496.

Newey, W. K. \& West, K. D. (1987), 'A simple, positive semidefinite, heteroskedasticity and autocorrelation consistent covariance matrix', Econometrica 55(3), 703-708.

Pindyck, R. S. \& Solimano, A. (1993), Economic instability and aggregate investment, NBER Working Papers 4380, National Bureau of Economic Research, Inc.

Pires, M. C. C. (2006), 'Credibilidade na política fiscal: uma análise preliminar para o brasil', Economia Aplicada 10(3), 367-375.

Ribeiro, M. B. \& Teixeira, J. R. (2001), 'An econometric analysis of privatesector investment in brazil', Cepal Review 74(153-166).

Rogoff, K. (1985), 'The optimal degree of commitment to an intermediate monetary target', The Quarterly Journal of Economics 100(4), 1169-1189.

Walsh, C. E. (1995), 'Optimal contracts for central bankers', The American Economic Review 85(1), 150-167.

Wooldridge, J. M. (2001), 'Applications of generalized method of moments estimation', Journal of Economic Perspectives 15(4), 87-100. 


\section{Apêndice A}

Tabela A.1: Teste de Estacionariedade

\begin{tabular}{lccccc}
\hline \multicolumn{5}{c}{ Kwiatkowisk-Phillips-Schimdt-Shin (KPSS) } \\
\hline Series & Bandwidth & Test & $\begin{array}{l}\text { 1\% critical } \\
\text { values }\end{array}$ & $\begin{array}{l}5 \% \text { critical } \\
\text { values }\end{array}$ & $\begin{array}{c}10 \% \text { critical } \\
\text { values }\end{array}$ \\
\hline cambio $_{e}$ & 5 & $0,202195^{b}$ & 0,216 & 0,146 & 0,119 \\
ci & 4 & $0,196695^{a}$ & 0,739 & 0,463 & 0,347 \\
credito & 4 & $0,121267^{b}$ & 0,216 & 0,146 & 0,119 \\
expinf & 4 & $0,220884^{b}$ & 0,216 & 0,146 & 0,119 \\
$D_{\text {expinf }}$ & 1 & $0,135909^{b}$ & 0,216 & 0,146 & 0,119 \\
hiato & 3 & $0,069428^{a}$ & 0,739 & 0,463 & 0,347 \\
iee & 2 & $0,065604^{a}$ & 0,739 & 0,463 & 0,347 \\
ice & 1 & $0,095544^{a}$ & 0,739 & 0,463 & 0,347 \\
icf & 5 & $0,171757^{b}$ & 0,216 & 0,146 & 0,119 \\
ir $_{\text {real }}$ & 3 & $0,070115^{b}$ & 0,216 & 0,146 & 0,119 \\
nn $_{g f c f}$ & 3 & $0,155929^{b}$ & 0,216 & 0,146 & 0,119 \\
selic & 3 & $0,094536^{b}$ & 0,216 & 0,146 & 0,119 \\
$y_{e}$ & 4 & $0,133819^{b}$ & 0,216 & 0,146 & 0,119 \\
sal $_{\text {real }}$ & 3 & $0,222569^{b}$ & 0,216 & 0,146 & 0,119 \\
$D_{\text {sal }}$ & 11 & $0,450487^{a}$ & 0,739 & 0,463 & 0,347 \\
\hline
\end{tabular}

Nota: $a$ denota constante e $b$ denota constante e tendencia. A escolha final pelo uso de intercepto e/ou tendência foi feita baseada no critério de Schwarz. A defasagem é o lag truncation escolhido para o Bartlett kernel. 
Tabela A.2: Estimações para os determinantes do investimento (MQO e GMM)

\begin{tabular}{|c|c|c|}
\hline \multicolumn{3}{|c|}{ Variável dependente: gfcf } \\
\hline Variáveis Explicativas & MQO & GMM \\
\hline constante & $\underset{(0,249086)}{10,47729^{* * *}}[42,06300]$ & $\begin{array}{c}10,54936^{* * *} \\
(0,200992)\end{array}$ \\
\hline$i c e_{-3}$ & $\begin{array}{l}0,005139^{* * * *}[3,200510] \\
(0,001606)\end{array}$ & $\begin{array}{l}0,004769^{* * * *}[4,274737] \\
(0,001116)\end{array}$ \\
\hline$i e e_{-1}$ & $\underset{(0,002752)}{0,007382^{* *}}[2,682797]$ & $\begin{array}{l}0,007493^{* * * *}[3,626820] \\
(0,002066)\end{array}$ \\
\hline hiato $_{\text {pibind }}$ & $\begin{array}{c}0,789722^{* *} \\
(0,392446)\end{array}[2,012310]$ & $\underset{(0,354097)}{0,829327^{* * *}}[2,342091]$ \\
\hline credito $_{-2}$ & $\underset{(0,003636)}{0,016864^{* * *}}[4,637764]$ & $\underset{(0,002866)}{0,016677^{* *}}[5,818580]$ \\
\hline$i r_{\text {real }}$ & $\begin{array}{r}-0,012383^{*} \\
(0,006829)\end{array}[-1,813299]$ & $\underset{(0,003993)}{-0,009342^{* *}}[-2,339464]$ \\
\hline cambio $_{-2}$ & $\begin{array}{l}-0,154836^{* * *}[-5,319125] \\
\quad(0,029109)\end{array}$ & $\begin{array}{l}-0,190739^{* * *}[-10,35722] \\
(0,018416)\end{array}$ \\
\hline crise & $\begin{array}{r}-0,061867^{*} \quad[-1,933210] \\
(0,032002)\end{array}$ & $\begin{array}{r}-0,072946^{*} \quad[-2,014022] \\
(0,036219)\end{array}$ \\
\hline Adjusted $R^{2}$ & 0,96 & 0,95 \\
\hline F-statistic (p-valor) & 0,00 & \\
\hline Ramsey - RESET (1)(p-value) & 0,1629 & \\
\hline Jarque-Bera (p-value) & 0,1211 & \\
\hline ARCH (1)(p-value) & 0,2435 & \\
\hline $\mathrm{LM}(1)(\mathrm{p}$-value $)$ & 0,3404 & \\
\hline J-statistic & & 7,6476 \\
\hline Prob (J-statistic) & & 0,57 \\
\hline Instrument rank & & 17 \\
\hline
\end{tabular}

Nota: erros-padrão entre parênteses e estatísticas t entre colchetes. Níveis de significância marginais: ${ }^{* * *}$ denota $1 \%,{ }^{* *}$ denota $5 \% \mathrm{e}^{*}$ denota $10 \%$. 